Silvana Alves Pereira

\title{
AVALIAÇÃO DA ACUIDADE VISUAL EM CRIANÇAS COM HIDROCEFALIA: UM ESTUDO ELETROFISIOLÓGICO POR POTENCIAL VISUAL EVOCADO DE VARREDURA.
}

São Paulo 2008 
Silvana Alves Pereira

\section{AVALIAÇÃO DA ACUIDADE VISUAL EM CRIANÇAS COM HIDROCEFALIA: UM ESTUDO ELETROFISIOLÓGICO POR POTENCIAL VISUAL EVOCADO DE VARREDURA.}

Dissertação apresentada ao Instituto de Psicologia da Universidade de São Paulo como parte dos requisitos para obtenção do título de Mestre em Psicologia.

Área de concentração: Neurociências e Comportamento Orientador: Prof $^{\circ}$. Dr $^{\circ}$. Marcelo Fernandes Costa

São Paulo 2008 
AUTORIZO A REPRODUÇÃO E DIVULGAÇÃO TOTAL OU PARCIAL DESTE TRABALHO, POR QUALQUER MEIO CONVENCIONAL OU ELETRÔNICO, PARA FINS DE ESTUDO E PESQUISA, DESDE QUE CITADA A FONTE.

Catalogação na publicação

Serviço de Biblioteca e Documentação

Instituto de Psicologia da Universidade de São Paulo

Pereira, Silvana Alves.

Avaliação da acuidade visual em crianças com hidrocefalia: um estudo eletrofisiológico por potencial visual evocado de varredura / Silvana Alves Pereira; orientador Marcelo Fernandes Costa. -- São Paulo, 2008.

$108 \mathrm{p}$.

Dissertação (Mestrado - Programa de Pós-Graduação em Psicologia. Área de Concentração: Neurociências e Comportamento) Instituto de Psicologia da Universidade de São Paulo.

1. Hidrocefalia 2. Derivação ventriculoperitoneal 3. Acuidade visual 4. Potenciais visuais evocados 5. Crianças I. Título.

RJ496.H9 
SILVANA ALVES PEREIRA

\section{AVALIAÇÃO DA ACUIDADE VISUAL EM CRIANÇAS COM HIDROCEFALIA: UM ESTUDO ELETROFISIOLÓGICO POR POTENCIAL VISUAL EVOCADO DE VARREDURA.}

Dissertação apresentada ao Instituto de Psicologia da universidade de São Paulo como parte dos requisitos para obtenção do título de Mestre em Psicologia, área de concentração Neurociências e Comportamento, para a comissão formada pelos seguintes professores:

Orientador:

Prof $^{\circ}$. Dr ${ }^{\circ}$ Marcelo Fernandes Costa Instituto de Psicologia, USP

Examinadores:

Prof $^{a}$. Dr ${ }^{a}$ Nielsy Helena Puglia Bergamasco Instituto de Psicologia, USP

Prof $^{\circ}$. Dr ${ }^{\circ}$ Albert Bousso Hospital Universitário, USP

Dissertação defendida e aprovada em: 


\section{DEDICATÓRIA}

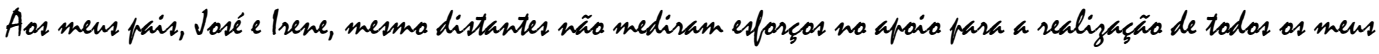
sonhos, minha eterna gratidãa por tuda que sempre fizeram, ofereceram e ensinaram.

Aos mens amoses e ismäos, Sandra e Nelson, que sempre me orgulham de suas conquistas e serwisam de fonte constante de inspiraçäa e forşa.

Aa amiga e companbeira, Gillesta, presente que os anjor me trouseram, exempla de otimisma e sabedoria, traduçäa do verdadeisa equilibria. Obrigada pela apaia e pelas palavsas de osientaşäa e sabedoria.

Aos amigas, Fabiane $A$ de Carvalba e Hensique P. Zani, que lagem minha vida em Anápolis mais alegre. Obrigada pelo incentiva e apoia wor mamentos de maior dificuldade.

Aa men eterna e fiel companheira, Mike, que cam toda a sen silência acompanhou minha luta em noites wãa dormidas.

Ao men "Anjo da Guarda", que muita contribium para que en chegasse até aqui, exempla de perseverança, amos e determinaçãa. Obrigada par ter acreditado tanto... 


\section{AGRADECIMENTOS}

Aa men querido arientador e amiga, Prof. Dr. Marcelo F. Casta. Pessoa admisável e exempla de dedicaşäa. Obrigada pelo casinha, confiança, oportunidade, paciência e ajuda, em todas as etapas deste trabalho. Agradeşa par ter estada presente nor mamentos mais dificeis desta jornada.

À Profa. Dra. Dosa F. Ventura, exempla de sabedoria e profissionalisma. Foi capaz de me mastrar qual o caminba a trilhas sempre que cheguei a alguma encrugilhada, sempre mostrando sespeita, paciencia e amizade.

Aa quesida e inesquecivel amiga, André G. F. de Oliveira, que me ensinon pacientemente todos os passos do PVE, estanda sempse wa men lada cam mita casinba e amizade.

À amiga, Viviane Sena, pelo que sempre esteve presente e pronta pasa me ajudar. Obrigada pela amizade e apaia constante na fase final deste trabalbo.

Á disetora da cussa de Fisioterapia da Unievangélica, Profa. Dra. Meire 1. Ribeira Soases, mulber dedicada e dinâmica. Obrigada pelas opartunidades que me den para a concretizas̆äa do men trabalho.

À Profa. e amiga Dra. Rübia Masiana da Silva, obrigada pela apaia, compreensãa e incentiva.

A Profa. Claudia Regina Major, pela amizade e apaia.

Aas demais colegas da Clínica de Pricalogia e Eletrofisiologia Visual e da Laboratiória de Pricofisiologia Sensorial que durante ester anos de estuda muito me ensinaram e auxiliaram na realizaşäa deste trabalha.

Aos demais docentes e colaboradoses da Unievangélica, que diseta on indisetamente muito me ajudaram nesta empreitada. 
Aos amigas e companheiros de traballa do Hospital Allest Einstein que me acompanharam e incentivaram na construçäa deste trabalho.

A todos os alunos, cam quem tive opartunidade de conviver e que sempre foram o estimula maior para men constante aperfeicoamento, a men mito dorigado.

As criangas e as suas familias, que mesmo em momentos dificeis e de sofrimenta, doaram-se incondicionalmente a este projeta.

A todas aqueles esquecidos, que diseta on indisetamente foram impartantes pass a realizašäa de um sonba.

Minha singela e eterna gratidãa... 
Bem aventurados os que compreendem o mev estranho passo a caminhare minhas mãos descoordenadas no aprender;

Bem aventurados os que sabem que meus ouvidos têm que se esforçar para compreenderem o que ouvem;

Bem aventurados os que olham e não vêem a comida que eu deixo cair fora do prato;

bem aventurados os que compreendem que, ainda que meus olhos brilhem, meu pensamento é lento e ás vezes confuso;

Bem aventurados os que nunca se lembram que hoje fiz a mesma pergunta três vezes;

Bem aventurados os que me escutam, pois eu também tenho algo a dizer;

Bem aventurados os que sabem o que sente o meu coração, embora eu nem sempre o possa expressar como gostaria;

Bem aventurados aqueles que, com muita paciência, tentam resolver minhas aflições e limitações, para que eu me sinta melhor no mundo;

Bem aventurados os que me aceitam e me amam como sou tão somente como sou, e não como muitos gostariam que eu fosse. 
RESUMO

\section{Pereira S.A. Avaliação da acuidade visual em crianças com hidrocefalia: um estudo eletrofisiológico por potencial visual evocado de varredura. (Dissertação de mestrado). Instituto de Psicologia, área de concentração Neurociências e comportamento- Universidade de São Paulo, 2008.}

O objetivo do estudo foi medir a acuidade visual (AV) em crianças com diagnóstico de hidrocefalia, apresentando ou não a válvula de derivação ventricular (DVP). Participaram da pesquisa um total de 55 crianças (34 F e 21M) com diagnóstico de hidrocefalia ( 45 com DVP e 10 sem DVP), com idade entre zero a 291 semanas (média 74 semanas). A AV foi medida pela técnica do Potencial Visual Evocado de Varredura e os resultados foram comparados a valores de referência (Norcia, 1985b). Os diagnósticos etiológicos que levaram à hidrocefalia foram: hemorragia intracraniana (25 crianças), mielomeningocele (20 crianças) e hidrocefalia congênita (10 crianças). O diagnóstico de hidrocefalia foi estabelecido em média no $16^{\circ}$ dia de vida. Verificamos que, 31 crianças tiveram o procedimento realizado com menos de 15 dias do diagnóstico de hidrocefalia enquanto que em 14 a válvula foi instalada após 15 dias. Das 55 crianças avaliadas no $1^{\circ}$ exame, 18 fizeram $02^{\circ}$ exame, 13 fizeram $03^{\circ}$ exame, 10 completaram quatro exames e apenas cinco completaram as cinco avaliações. Os resultados mostram que dentre as 101 avaliações de $A V$ realizadas em todas as crianças, 95 exames (94\%) se mostraram alterados e seis normais. Não há diferença estatística entre a AV das crianças sem derivação em comparação com aquelas crianças cuja DVP foi realizada com tempo de derivação maior que 15 dias $(p=0.699)$. Houve, todavia, uma diferença estatística na AV, quando comparamos as crianças, cujas derivações foram realizadas em até 15 dias do diagnóstico da hidrocefalia, com aquelas cuja derivação foi realizada após 15 dias $(p=0.038)$ ou com aquelas que não foram derivadas $(p=0.031)$. Crianças que não tiveram complicações na DVP tiveram um melhor resultado de $A V$ quando comparado com o grupo com complicação $(p=0.0001)$. No grupo de crianças com complicação, novamente aquelas que foram derivadas com tempo inferior a 15 dias do diagnóstico da hidrocefalia apresentou melhores resultados de AV quando comparado com aquelas crianças com complicação cuja derivação foi realizada com mais de 15 dias $(p=0.029)$. Nós concluímos que é possível a medida da acuidade visual de resolução pelos PVEs de varredura em crianças com diagnóstico de hidrocefalia e os valores geralmente são piores comparando aos valores normativos. O tempo da derivação e o número de complicações decorrentes da DVP parecem interferir nesta diferença. Em nosso conhecimento, este foi o primeiro trabalho a avaliar progressivamente, a acuidade visual de crianças, nos primeiros anos de vida, com hidrocefalia, com ou sem DVP e correlacionar o resultado com o tempo de derivação e número de complicações. Apesar da grande evolução tecnológica alcançada pela oftalmologia, ainda não somos capazes de prevenir as alterações visuais detectáveis pelo simples exame de AV nas crianças com hidrocefalia. O tempo para a inserção da válvula de derivação e o tratamento para as complicações ainda são medidas retardadas devido à prematuridade, instabilidade hemodinâmica e a não autorização do familiar. Estes motivos podem comprometer o desenvolvimento visual destas crianças.

Palavras chaves: Hidrocefalia, Derivação ventricular, Acuidade visual, Potencial visual evocado de varredura, Crianças. 


\section{ABSTRACT}

\section{Pereira SA. Visual acuity evaluation in children with hydrocephalus: an electrophysiological study with sweep visual evoked potential.}

The objective was to measure the visual acuity (VA) of children with the diagnosis of hydrocephalus with or without peritoneal-ventricular shunt (PVS). A total of 55 children with the diagnosis of hydrocephalus ( 45 with PVS and 10 without PVS) were included in the study (34F and $21 \mathrm{M}$ ), with an age range of o to 291 weeks (mean $=74$ weeks). The VA was measured by the sweep visual evoked potential technique and the results were compared with reference values proposed by Norcia (1985b). Etiological diagnosis of the hydrocephalus was as follows: intracranial hemorrhage ( 25 children), meningomyelocele (20 children) and congenital hydrocephalus (10 children). The diagnosis of hydrocephalus was made in an average time of 16 days of life. After the diagnosis, the insertion of the PVS, when made, was accomplished in average on the $16^{\text {th }}$ day. Of those with a PVS, in 31 the ventricular valve was inserted before 15 days after the diagnosis whereas in 14 in shunt was inserted after 15 days. Of the 55 children evaluated in the first exam, 18 were evaluated in a second exam, 13 did the third exam, 10 completed 4 exams and only 5 completed the 5 evaluations. The results of the 101 sweep visual evoked potential performed in all children, 95 exams (94\%) were abnormal and only 6 were normal. There was no statistical difference in the VA of children without a ventricular shunt in comparison with those in which the shunt was inserted after 15 days of the diagnosis of hydrocephalus $(p=0.699)$. There was, however, a statistical difference in the VA between children with a ventricular shunt inserted before 15 days of the diagnosis and children with a ventricular shunt after 15 days $(p=0.038)$ or those without a shunt $(p=0.031)$. Children with no complications of the ventricular shunt had a better VA as compared to those with shunt complications $(p=0.0001$ ). In the group of children with complications, again those who had a shunt inserted before 15 days bad better VA results in comparison to those in whom the shunt was inserted after 15 days $(p=0.029)$. We concluded that measuring visual acuity by sweep visual evoked potential is feasible in children with the diagnosis of hydrocephalus and that results are usually worse comparing with reference values. The timing for insertion of a ventricular shunt and the occurrence of complications of this procedure are factors that may influence the VA. To our knowledge, this is the first study that progressively evaluated the VA in children, of early age, with hydrocephalus, with or without a ventricular shunt and correlated the VA with the timing and complications of the ventricular shunt. Despite the great technological advance in ophthalmology, we are still unable to prevent visual impairments, detectable by simple visual acuity tests, in children with hydrocephalus. The timing of the insertion of the ventricular shunt and the adequate treatment of the potential complications may be delayed due to prematurity, hemodynamic instability and family refusal. This delay may compromise the visual development of these children.

Keywords: Hydrocephalus, ventricular shunt, visual acuity, scanned visual evoked potential, children. 


\section{ABREVIAÇÕES}

LCR - $\quad$ Líquido Cefalorraquidiano

ESA - Espaço Subaracnóideo

HIC - Hemorragia Intracraniana

EBA - Espinha Bífida Aberta

EBO - Espinha Bífida Oculta

EUA - Estados Unidos da América

RNPT - Recém Nascidos Prematuros

US - $\quad$ Ultra-som

CT - Tomografia Computadorizada

RNM - Ressonância Neuro Magnética

AV - $\quad$ Acuidade Visual

MAR - Mínimo Ângulo de Resolução

PVE - Potencial Visual Evocado

PVEV - Potenciais Visuais de Varredura de Freqüência Espaciais

DVP - Derivação Ventrículo-peritoneal

NUDIVA - Digital Infant Visual Assessment

HZ - Hertz

db - Decibéis

$\mathrm{cm}$ - Centímetros

EEG - Eletroencefalograma

SNR - Relação Sinal por Ruído

$\log$ - Logaritmo

cpg - Ciclos porgrau

logMAR - Logaritmo do menor ângulo de resolução

IdC - Idade Corrigida

IdR - Idade real no momento do exame

IG - Idade Gestacional

WHO - Organização Mundial de Saúde 


\section{LISTA TABELAS}

Tabela 1 - Dados para varredura no PVEV. Valores iniciais e finais de varredura para as diferentes faixas etárias. (Fonte: NORCIA, 1985b).

Tabela $2 \quad$ - Tabela de referência. Valores de referência para acuidade visual em logMAR e equivalentes em Snellen. (Fonte: NORCIA, 1985b).

Tabela 3 - Dados demográficos da casuística........................................5

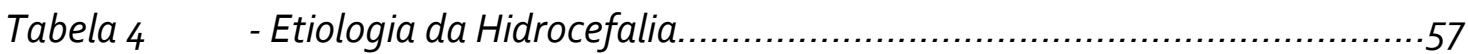

Tabela 5 - Características da abordagem terapêutica......................................59

Tabela 6 - Complicações encontradas nas 45 crianças com DVP.......................65

Tabela 7 - Evolução da variável complicação ao longo do exame........................66

Tabela 8 - Complicações presentes nos cinco exames de PVE das 45 crianças derivadas. 


\section{LISTA FIGURAS}

Figura 1 - Representação anatômica do LCR e ventrículos cerebrais

Figura 2 - Freqüência espacial é a medida dos números de ciclos por grau subtendido na retina. (a) um ciclo por grau. (b) dois ciclos por grau.

Figura 3 - Tabela de Snellen .31

Figura 4 - Posicionamento dos eletrodos na região cefálica .44

Figura 5 - Estímulo de grades apresentado para a criança.......................................45

Figura 6 - Desenho esquemático do Sistema utilizado para registro do PVE.

Figura 7 - Registro de um resultado obtido na medida de AV.

Figura 8 - Registro real de avaliação dos registros obtidos

Figura 9 - Freqüência dos pacientes durante os cinco exames realizados. 61

Figura 10 - Total de avaliações realizadas durante o estudo, separados por grupos.

Figura 11 - Comparação entre os grupos com diferentes tipos de intervenção. .64

Figura 12 - Comparação da AV durante $01^{\circ}$ exame entre os grupos sem complicação.

Figura13 - Evolução da AV entre os dois primeiros exames das 5 crianças que apresetaram 
complicações no $1^{\circ}$ e não no $2^{\circ}$ exame.

Figura 14 - Média da AV entre os dois primeiros exames das 5 crianças que apresetaram complicações no $1^{\circ}$ exame.

Figura 15 - Média da AV das sete crianças que apresetaram complicações no $2^{\circ}$ e $3^{\circ}$ exames.

Figura 16 - Média da AV das duas crianças que apresetaram complicações somente em um momento da avaliação visual.

Figura 17 - Comparação da AV das 37 crianças que derivaram e complicaram durante $01^{\circ}$ exame. .76

Figura 18 - Média da AV das 10 crianças que não derivaram. .77

Figura 19 - Classificação da idade gestacional e resultado de AV no $1^{\circ}$ exame. .78

Figura 20 - Diferentes etiologias e resultado de $A V$ no $1^{\circ}$ exame. .79 
SUMÁRIO

1. O INTRODUÇÃO.

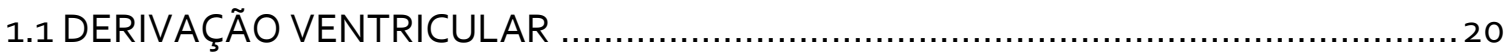

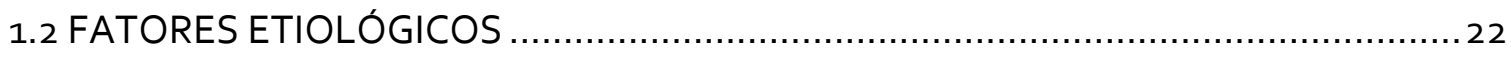

1.2.1 ESPINHA BÍFIDA______________________ 22

1.2.2 HEMORRAGIA INTRACRANIANA (HIC) _ 25

1.2.3 HIDROCEFALIA CONGÊNITA ___ 28

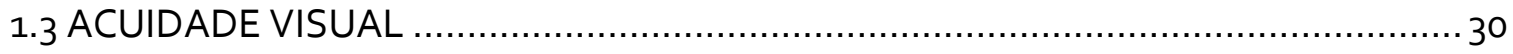

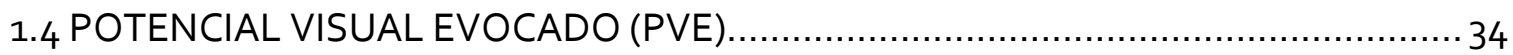

1.4.1 POTENCIAL VISUAL EVOCADO DE VARREDURA ___ 36

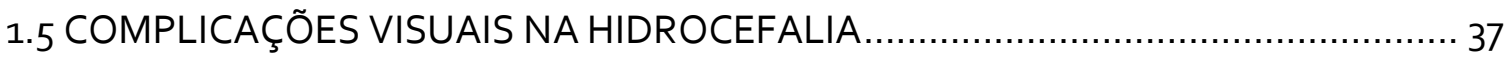

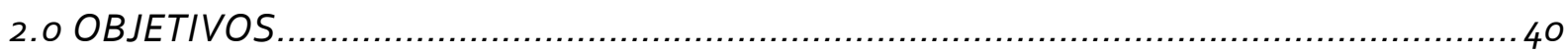

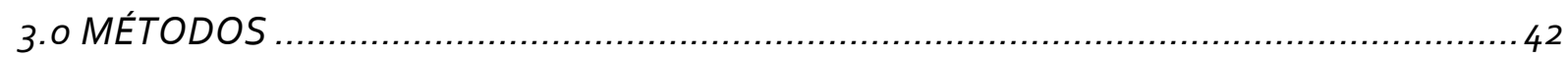

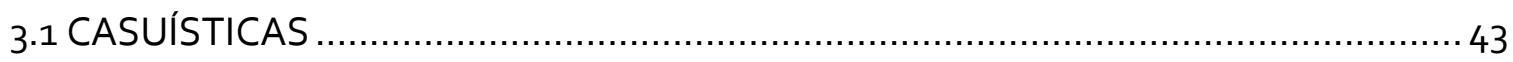

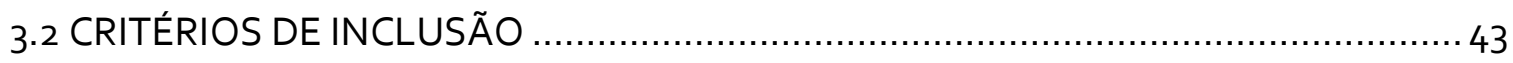

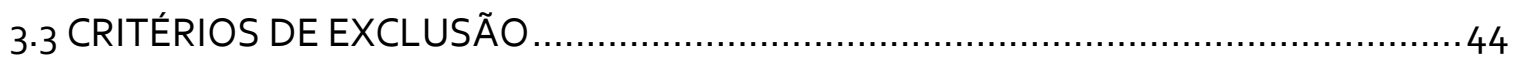

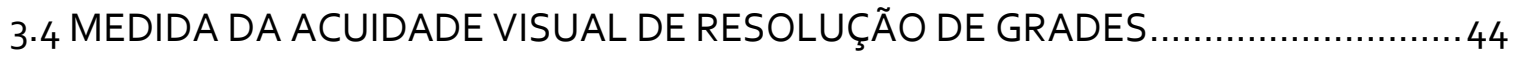

3.4.1 EQUIPAMENTO DE REGISTROS ___ 46

3.4.2 MONITOR____ 47

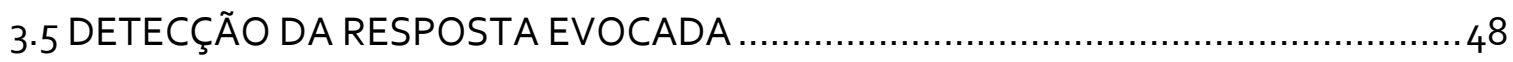

3.5.1 CRITÉRIO DE REGISTRO PELA RELAÇÃO SINAL/RUÍDO____ 48

3.5.2 CARACTERÍSTICA DA FASE DO POTENCIAL VISUAL EVOCADO ___ 49 


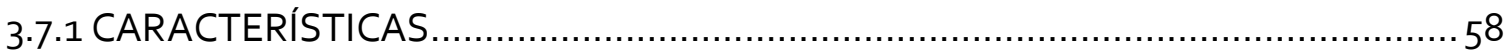

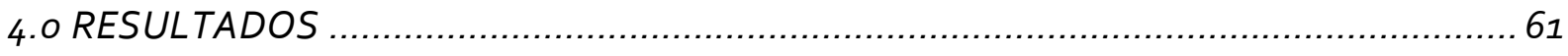

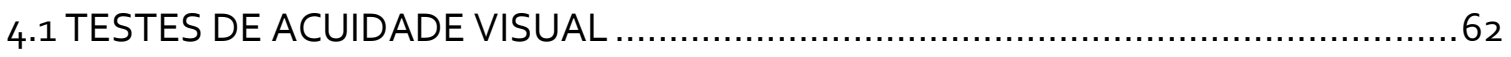

4.1.1 ADERÊNCIA ÀS AVALIAÇÕES DE ACUIDADE VISUAL____ 62

4.1.2 RESULTADO DOS TESTES DE ACUIDADE VISUAL NAS 5 AVALIAÇÕES _ 63

4.2 TEMPO DE DERIVAÇÃO ___ _ 64

4.3 COMPLICAÇÕES NO $1^{\circ} \mathrm{E}^{\circ}$ EXAME__________________ 66

4.3.1 COMPLICAÇÕES NO $2^{\circ} \mathrm{E} 3^{\circ}$ EXAME ___ 73

4.3.2 COMPLICAÇÕES E TEMPO DE DERIVAÇÃO____ 76

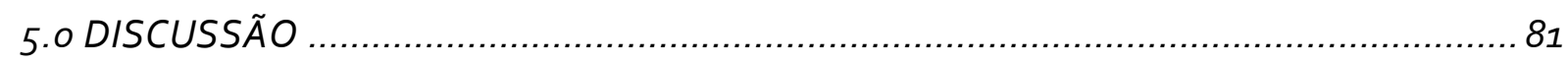

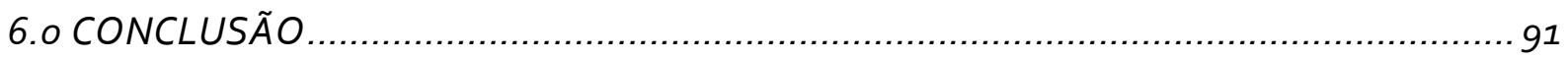

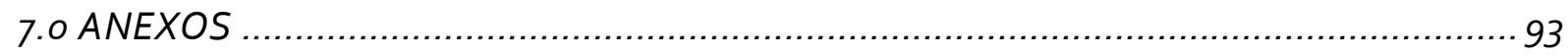

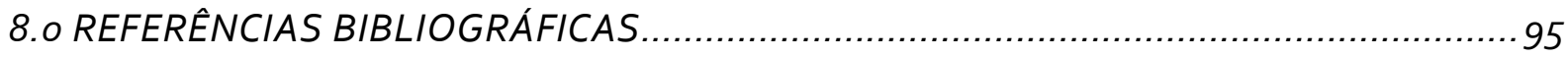


1. O INTRODUÇÃO 


\subsection{INTRODUÇÃO}

termo hidrocefalia vem do grego e significa "água na cabeça". É a condição
na qual há acúmulo de líquido cefalorraquidiano (LCR). O LCR é um líquido constantemente produzido pelo plexo coróide dos ventrículos cerebrais. O fluxo de LCR atravessa o sistema ventricular (dois ventrículos laterais, o terceiro ventrículo, o aqueduto de Sylvius e o quarto ventrículo), até alcançar o espaço subaracnóideo (ESA) pelo aparato medial e lateral do quarto ventrículo, e então banha a superfície do cérebro e espinha e é reabsorvido no sistema sanguíneo pelas veias aracnóides do sistema venoso intracraniano (Tzekov; Cherninkova, 1991-92) (Figura 1).

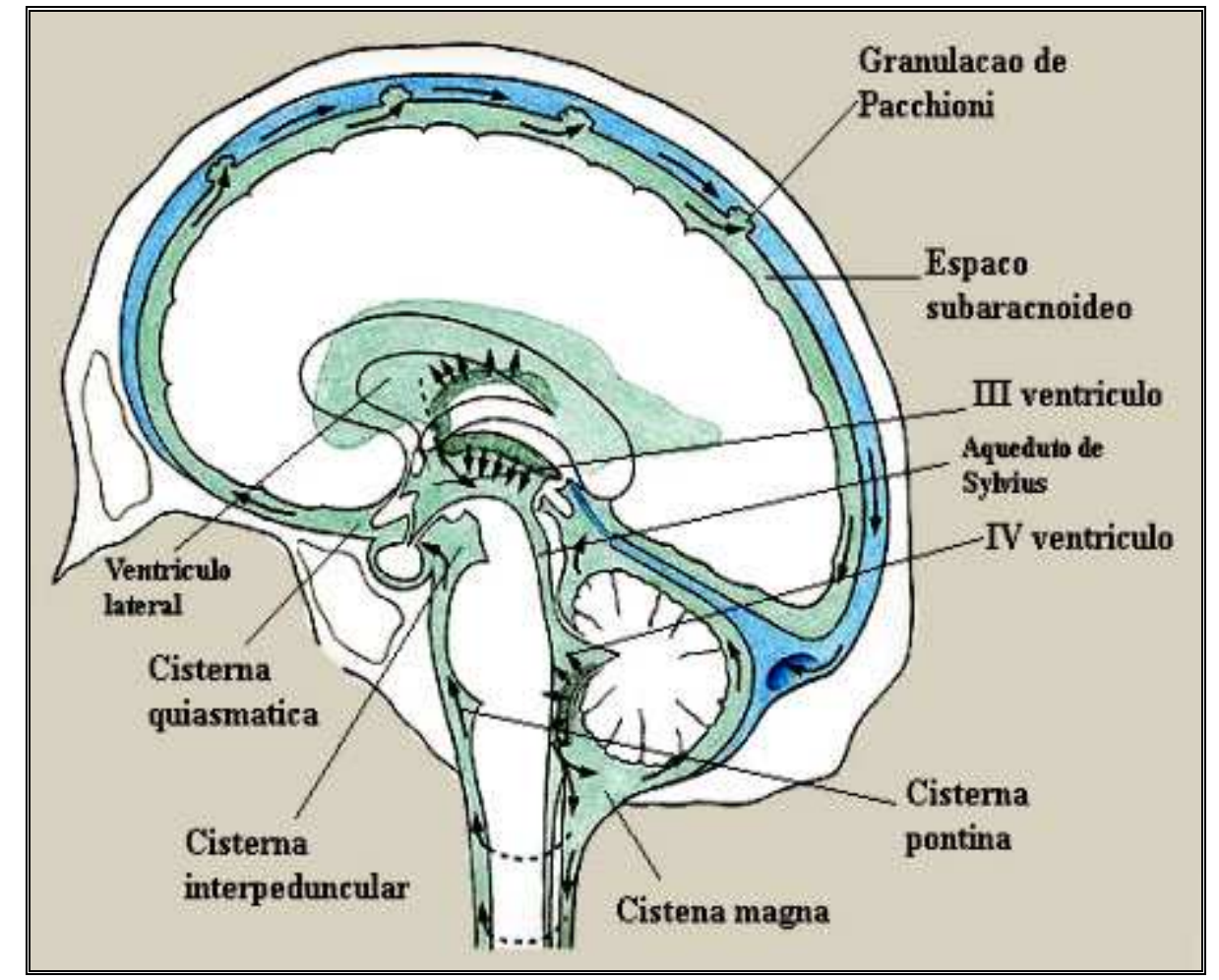

Figura 1: Representação anatômica do LCR e ventrículos cerebrais. http://images.google.com.br/imgres?imgurl=http://esclerosemultipla.files.wordpress.com/2006/ 
Esta reabsorção realiza-se por veias especializadas dentro do crânio as quais têm uma superfície semelhante a uma peneira. Apesar de muito mais lentamente que a circulação do sangue, o LCR está em constante produção, circulação e reabsorção.

A hidrocefalia pode, portanto, resultar de excesso de produção de LCR (raro), ou quando é impedida a sua circulação ou absorção. Nesta situação, em que o LCR é constantemente produzido, mas não consegue circular, ele se acumula e causa um aumento da pressão no interior do cérebro. Os ventrículos dilatam e o tecido cerebral sofre compressão. Em bebês os ossos do crânio não estão fixos, resultando no crescimento da cabeça.

A característica clínica, principalmente nos primeiros meses de vida, é o aumento do volume craniano detectado através de medidas semanais ou até diárias do perímetro cefálico, acompanhado com o auxílio de curvas apropriadas e através de exames de imagem.

Além do aumento do perímetro cefálico, a hidrocefalia altera a concentração de diversos neurotransmissores neuropeptídios, provocando distúrbio difuso da função neuronal e possivelmente a dificuldade de circulação dos metabólicos do cérebro hidrocefálico (Cedzich; Schramm; Wenzel, 1990).

Depois do nascimento a progressão da hidrocefalia pode elevar a tração e angulação do nervo óptico e afinar o córtex visual e a pressão do cérebro mais tarde afetar o terceiro e quarto pares de nervos cranianos e levar ao sinal, comumente, conhecido como "sol poente" (depressão, abdução e retração palpebral em ambos os olhos). Clinicamente, uma 
criança que persiste com o sinal do sol poente por mais de três meses apresenta grandes chances de ter sérios danos cerebrais (Gaston, 1991).

Crianças com diagnóstico de hidrocefalia frequentemente apresentam, além das alterações visuais e oculares, que são sinais muito evidentes desde os primeiros estágios da patologia, falhas no desenvolvimento das funções cognitivas, porém é insuficientemente compreendido o papel das anormalidades neuropatológicas e das complicações decorrentes da hidrocefalia na gênese das alterações (Cedzich; Schramm; Wenzel, 1990).

Por ser a hidrocefalia uma condição patológica que gera danos oculares e cognitivos o seu tratamento tem sido revolucionário desde a introdução da implantação cirúrgica de uma válvula artificial (derivação ventricular), com o objetivo de controlar os mecanismos de drenagem do LCR do ventrículo lateral do cérebro para: o átrio direito do coração ou para a cavidade peritoneal.

\subsection{DERIVAÇÃO VENTRICULAR}

Antes do século XIX o tratamento para hidrocefalia era mais observacional. Hipócrates foi o primeiro médico a realizar a punção ventricular e nesta época eles ainda acreditavam que o líquido estava acumulado no espaço extra-axial (Drake; Sainte-Rose, 1995).

Vesalius (1514-1564) quantificou muito das características anatômicas e patológicas da hidrocefalia. A descrição para a hidrocefalia era "um acumulo de água entre as membranas e não entre os sulcos" e em 1664. Thomas Willis sugeriu que a produção do LCR 
ocorria no plexo coróide. Devido ao pobre entendimento da fisiopatologia da hidrocefalia no século XVIII, os tratamentos iniciais foram esporádicos e sem bons resultados. Muitos tratamentos incluíram múltiplas medicações e purgativos, diuréticos, injeção de iodo intraventricular, enfaixamento da cabeça, sangria, trepanação de crânio e uso da ligação da artéria carótida. (Drake; Sainte-Rose, 1995).

Paralelo a evolução do entendimento fisiopatológico da hidrocefalia está o avanço das tentativas cirúrgicas realizadas para conter o processo patológico. Em 1891, Quincke descreveu pela primeira vez a punção lombar como tratamento eficaz para a hidrocefalia. Miculicz foi o primeiro a drenar o ventrículo lateral para o espaço subgaleal, subdural e subaracnóideo com o uso de tubo de ouro e fios de sutura a base de intestino de gatos. (Mccullough, 1990).

Após esta data muitos outros trabalhos descrevem tentativas de drenar o excesso de LCR, porém somente em 1952, primeiramente com Nulsen and Spitz e posteriormente com muitos outros médicos à técnica de drenagem peritoneal foi realizada (Drake; Sainte-Rose, 1995).

Com o avanço da tecnologia de imagem e avanços nos materiais usados a técnica de drenagem ventrículo-peritoneal tem sido aprimorada e usada difusamente em quase $100 \%$ dos casos de hidrocefalia descompensada (Roth; Cohen, 1996).

Mesmo aprimorada a derivação ainda tem muitas complicações como: malformações mecânicas (obstruções ou hiperderivações) e infecções. Porém o aumento da pressão intracraniana em pacientes com hidrocefalia pode produzir complicações ainda maiores, como, por exemplo, distúrbios visuais (Sutton; Sun; Adzick, 2001). 
A real incidência da perda da visão não é conhecida. Muitos estudos são sobre as complicações da derivação, mas a perda da visão como uma complicação não tem sido mencionada em nenhum destes. As alterações visuais estão apresentadas nas próximas sessões.

Com relação aos fatores etiológicos mais comumente relacionados à hidrocefalia, a Espinha Bífida, uma patologia que afeta a medula espinhal, está descrita como a patologia mais freqüente. No estudo feito por Gaston , (1991) com 322 pacientes com diagnóstico de Espinha Bífida, 249 pacientes apresentavam hidrocefalia.

Além da Espinha bífida a hidrocefalia pode estar relacionada com a Hemorragia Intracraniana (HIC), ou ser uma condição patológica única, sendo então, classificada como Hidrocefalia Congênita.

\subsection{FATORES ETIOLÓGICOS}

\subsubsection{ESPINHA BÍFIDA}

Espinha Bífida é a designação usada universalmente como sinônimo de disrafismo espinal (termo genérico reintroduzido na literatura médica por Liechtenstein em 1940). Nessa condição, geralmente não há fusão dos arcos vertebrais posteriores. (Delisa, 1992).

Classicamente, essa entidade é dividida em duas formas clínicas, a espinha bífida aberta (EBA) e a espinha bífida oculta (EBO). Na variedade aberta o defeito é franco e aparente ao nascimento e na oculta, a malformação não é aparente e não acompanhada de significado clínico ao nascimento. No presente estudo um tipo da EBA será detalhado, também conhecido como mielomeningocele (Mielo) (Greve, 2001). 
A Mielo é uma das lesões congênitas mais comuns da medula espinhal, uma vez que as crianças afetadas usualmente sobrevivem por longos meses e anos (Rosemberg, 1997).

A Mielo é também um dos mais comuns defeitos ao nascimento, com uma freqüência de 0,4 a 1/1000 nascidos vivos nos EUA (Fobe et al., 1999). No Brasil não temos dados estatísticos da Mielo. O hospital Sarah, em Brasília, registrou o nascimento de 109 crianças com Mielo em 1999, 113 em 2000 e 109 em 2001(Hospital Sarah). Em Campinas, a incidência registrada pelo programa de Estudo Colaborativo Latino-Americano de Malformações Congênitas (ECLAMC), durante o período entre 1982 a 1998, a incidência registrada de hidrocefalia foi de 0,74 a 1.000 nascidos vivos (Cavalcanti; Salomão, 2003).

A mielo é uma malformação do conteúdo do canal raquidiano decorrente do defeito de fechamento da porção posterior do tubo neural. Em 80\% ocorrem na região lombar, sendo o restante, por ordem de freqüência, torácica, cervical e sacral.

No recém-nascido essa malformação assume aspecto cístico. É constituída por tecido nervoso medular. Circundando essa área há finas membranas papiráceas e escamosas, constituídas por restos de meninges alteradas que se unem perifericamente à pele normal. O grau de abaulamento do cisto depende da quantidade de LCR que há no seu interior e a gravidade das seqüelas são maiores nos casos mais altos (cervical, torácica e lombar) (Shepherd, 1996).

Classicamente, as mielo torácicas causam hidrocefalia em 100\% dos casos, as lombotorácicas em 90\%, as lombares em 78\%, as lombossacras em $60 \%$ e as sacrais em 50\%. As causas da hidrocefalia são variadas. Esta associação é responsável por quadros 
neurológicos geralmente graves, levando a uma perda sensório-motora das regiões servidas pelos tecidos nervosos a partir do local da lesão (Delisa,1992).

A etiologia mais freqüente da hidrocefalia é a malformação do espaço subaracnóideo, associada à anormalidade do aqueduto e a malformação de Arnold-Chiari, caracterizada por um deslocamento caudal do bulbo e parte inferior do cerebelo que vêm se colocar no interior do canal raquiano. Os primeiros segmentos da medula espinhal, geralmente hipoplásicos, também se acham rebaixados, de modo que as raízes nervosas apresentam um trajeto inverso, oblíquo para cima. A própria ponte é hipoplásica e o IV ventrículo, estreito e laminado. Em mais de 50\% dos casos, há estenose de aqueduto e deformação anterior do mesencéfalo, em forma de quilha de navio (Rosemberg, 1998).

A hidrocefalia pode estar patente por ocasião do nascimento ou se manifestar mais tarde, sendo que as maiores estatísticas mostram que a hidrocefalia é complicação de 90\% dos casos de mielo e que por volta do quarto mês é evidente, com ou sem fechamento da malformação.

Como a etiologia da Mielo ainda permanece desconhecida, uma política de prevenção não pode repousar em bases sólidas. Estudos epidemiológicos sugerem que os estados disráficos se devam a fatores multifatoriais, dentre os quais o ambiente (maior freqüência em certos países como Irlanda e País de Gales, e em classes sociais mais baixas, certos períodos epidêmicos, tendência declinante da ocorrência em certos países, influência experimental de agentes teratogênicos) e fatores genéticos (incidência maior em gêmeos, maior risco de recorrência - 5\% em média - após o nascimento de uma primeira criança, herança autossômica recessiva constatada em algumas síndromes) (Fobe et al.,1999). 
O sistema visual é alvo de distúrbios associados à Mielo. Estudos têm demonstrado que as crianças com Mielo associada à hidrocefalia, cerca de 60-75\% apresentam algum distúrbio óculo motor, como por exemplo, o estrabismo. Uma das primeiras descrições de estrabismo em conjunto com a hidrocefalia foi feita por Robert Whytt em 1768.

Caines; Dahl; Holmstro, (2007), mostrou em seu estudo, que de 21 crianças com diagnóstico de Mielo, 9 tinham o diagnóstico de hidrocefalia não derivada e também apresentaram estrabismo. Cronemberger et al (1999) dos 72 pacientes com Mielo, com idade variando de 5 meses a 18 anos, $64(88,9 \%)$ pacientes tinham hidrocefalia. Destes 64 pacientes, $36(56,3 \%)$ tinham estrabismo, sendo que $21(58,3 \%)$ eram endotrópicos, 13 $(36,1 \%)$ exotrópicos, 1 (2,8\%) exofórico e 1 (2,8\%) com estrabismo discinético. Do total dos 72 pacientes estudados 38 (52,8\%) eram estrábicos.

O único trabalho encontrado que estuda o tempo da derivação e suas possíveis alterações, foi realizado por Fobe et al (1999). O objetivo do trabalho foi investigar as alterações cognitivas. Estes autores mostraram que o melhor resultado cognitivo está nas crianças que derivam até sete dias de vida, decrescendo progressivamente a partir do primeiro mês. Os resultados positivos na derivação precoce são devidos à possibilidade de reversão dos efeitos deletérios que a hidrocefalia exerce tanto no corpo caloso como na substância branca.

\subsubsection{HEMORRAGIA INTRACRANIANA (HIC)}

A HIC é uma hemorragia cerebral que se origina na matriz germinativa de recém nascidos prematuros (RNPT). É a principal patologia neurológica do recém-nascido. Ela é 
um dos mais importantes fatores etiológicos associados à hidrocefalia adquirida (Harvey et al, 1997)

Existem várias classificações para a HIC. Uma das classificações mais utilizadas foi criada por Papile et al (1978), que classificou a HIC como:

Grau I: hemorragia subependimária.

Graull: hemorragia intra ventricular sem dilatação ventricular

Graulll: hemorragia intra ventricular com dilatação.

GraulV: hemorragia intra ventricular com hemorragia parenquimatosa.

Estudos de RNPT na primeira infância indicam que a HIC pode estar associada com déficits de acuidade visual. (Reinprecht, et al, 2001).

Estudos posteriores confirmam que o déficit da acuidade visual ocorre em alguns bebês com HIC, entretanto, os déficits são mais prevalentes entre os bebês com lesões isquêmicas, como a leucomalácia, do que entre os com lesão hemorrágica, devido a extensa área do cérebro acometida e possivelmente a dificuldade de circulação dos metabólicos do cérebro hidrocefálico. (Reinprecht, et al, 2001).

Respostas visuais de crianças com HIC têm sido pouco estudadas. Pike et al 1994, avaliaram a visão em crianças nascidas prematuras com idade de 2-9 anos e encontraram baixa acuidade visual. Destas, todas eram diagnosticadas como tendo HIC.

King and Cronin (1993) encontraram déficit de acuidade visual em 5 de 13 crianças com HIC grau IV seguidas por um período de até 3-7 anos e comparadas com 9 crianças com 
mesmo peso e idade gestacional. Assim como outros trabalhos, os dados sugerem que as crianças com HIC severa são de risco para déficit visual.

Entretanto, poucas informações sobre respostas visuais são avaliadas longitudinalmente em crianças com HIC severa, ou no desenvolvimento da visão em crianças com HIC e hidrocefalia. Não foram encontrados estudos que comparam a HIC com hidrocefalia ao desempenho em testes visuais.

Reinprecht, et al (2001), analisaram as complicações da derivação e realizaram acompanhamento longitudinal em 76 crianças com diagnóstico de HIC, no período de 1984 a 1999 e concluíram que:

- a freqüência de déficit no campo visual foi significantemente mais comum em sujeitos com grau III e IV do que nos de grau I e II.

- bebês com HIC têm risco de desenvolver dano na acuidade visual durante o primeiro ano.

- os bebês com HIC apresentam um risco maior de redução da acuidade visual aos quatro anos.

- o desenvolvimento do campo visual é prejudicado entre os bebês com HIC, mas somente até eles alcançarem um ano e meio de idade.

- a piora da acuidade visual está relacionada com o número de vezes de re-derivação; quanto mais troca, pior o prognóstico.

Sendo a hidrocefalia uma das possíveis seqüelas da HIC o seu tratamento é uma emergência neurocirúrgica e inclui a monitoração das cavidades cerebrais (ventrículos) 
através de ultra-som (US) e tomografia (CT) ou ressonância neuro magnética (RNM) afim de avaliar os seus respectivos graus. Caso haja necessidade realiza-se a derivação ventricular com o objetivo de se estabilizar a pressão intracraniana exercida sobre o córtex cerebral. A hidrocefalia pós-HIC requer derivação cerca de $20 \%$ de crianças, porém, a derivação realizada precocemente tem sido abandonada nestes pacientes devido à alta incidência de complicações pós-cirúrgicas, como a infecção e a obstrução da válvula (Reinprecht et al, 2001).

A prematuridade desses pacientes e seu sistema imunológico incompetente favorecem a infecção da derivação- há aumento dos níveis de proteína no LCR e obstrução. A obstrução foi a mais comum complicação encontrada no estudo feito por Reinprecht et al, 2001.

Mesmo sendo abandonada por muitos cirurgiões, a derivação, para o tratamento da HIC, ainda é o método mais utilizado, apesar de suas possíveis complicações. Quando esta estratégia é usada, o sucesso da derivação parece ser determinado pela severidade do prognóstico da patologia e está influenciada, principalmente, pela experiência cirúrgica e pela exploração das tecnologias modernas.

No estudo de Mankinen et al 1987, a idade gestacional baixa e o peso de nascimento baixo foram fatores que não influenciaram a relação das complicações e respostas devido à estratégia cirúrgica poder ser adaptada.

\subsubsection{HIDROCEFALIA ISOLADA OU CONGÊNITA}


A incidência de hidrocefalia congênita varia muito, o que pode ser justificado pela inclusão ou exclusão de natimortos, de crianças com espinha bífida e de casos com manifestação da hidrocefalia no período pós-natal. Stein et al (1989) estimaram que taxas de $54 \%$ a 60\%, respectivamente, correspondem à incidência de hidrocéfalos congênitos que nascem mortos. Portanto, se tomarmos como denominador somente os nascimentos vivos, estamos subestimando a incidência real desta malformação (Matushita, Almeida, 1992).

As hidrocefalias congênitas denotam situações que se iniciam na vida intra-uterina e se manifestam, na sua maioria, já na fase fetal ou logo após o nascimento. É um estado anormal decorrente de muitas causas. O seu quadro clínico raramente reflete a condição básica que a determinou. As hidrocefalias congênitas, dependendo da natureza dos mecanismos de compensação e da evolução do processo ativo, apresentam quadros clínicos diversos nas diferentes faixas etárias (Matushita, Almeida, 1992).

As hidrocefalias congênitas verdadeiras, isto é, com acentuado aumento do perímetro cefálico presente ao nascimento são raramente compatíveis com boa qualidade de vida pós-natal. Cerca de metade dos casos de hidrocefalia congênita, de importância clínica, apresenta crescimento anormal da cabeça após o nascimento.

Assim como a hidrocefalia associada à Mielo, a hidrocefalia congênita também gera danos irreparáveis para o sistema visual, porém não foram encontrados estudos que avaliem este grupo de crianças. 
O procedimento de medida da eficiência do sistema visual mais comum entre todos os utilizados em Oftalmologia é o teste de acuidade visual (AV) (Atkinson \& Braddick, 1989; Odom, 2003). A AV ao nascimento é tão pobre que um adulto com o nível de AV de um recém - nascido é considerado legalmente como cego (Slater, 1989).

A AV pode ser definida, segundo ordenação psicobiológica, como a função visual que exprime a capacidade discriminativa de formas; ou segundo ordenações operacionais como o método com que se mede o reconhecimento da separação angular entre dois pontos no espaço; ou que se mede a resolução visual de suas respectivas imagens sobre a retina (Bicas, 2002).

Quando estímulos periódicos, tais como grades de ondas quadradas ou senóides, são utilizados para a avaliação da acuidade visual, o valor resultante da capacidade de resolução é dado na unidade denominada ciclos por grau de ângulo visual (ciclos/grau). Cada ciclo é formado por duas barras, uma clara e uma escura, e o número de ciclos que ocupam um grau de ângulo visual é denominado freqüência espacial (Figura 2). 


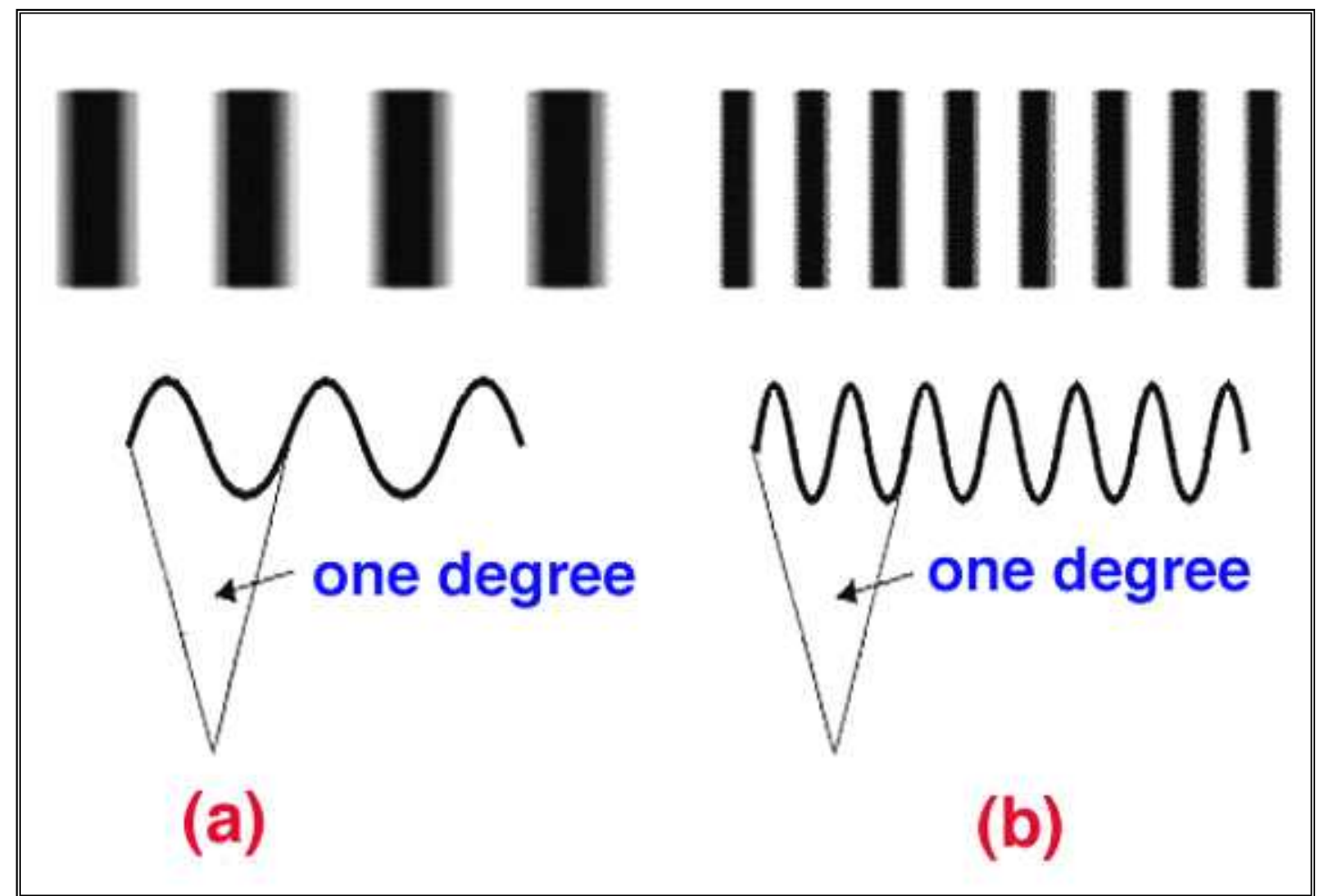

Figura 2: Freqüência espacial é a medida dos números de ciclos por grau subtendido na retina. (a) um ciclo por grau. (b) dois ciclos por grau. http://webvision.med.utah.edu/kallSpatial.html.

Um ciclo em um grau significa que cada barra tem 30 minutos e, portanto, para converter qualquer valor de ciclos/grau em minutos de arco deve-se dividir 30 pelo valor de ciclos/grau. A acuidade visual de resolução de um adulto normal é de, pelo menos, 30 ciclo/grau (Salomão; Birch, 1996).

Para a medida convencional clínica da AV caracteres visuais chamados optotipos (letras e símbolos) são apresentados em tabelas e o paciente é solicitado a informar a resolução de detalhes destes optotipos, ou seja, o sujeito deve reconhecer um símbolo e emitir uma resposta verbal para informar o quanto enxerga. Estes são apresentados em um contraste muito alto, e à medida que as respostas corretas são obtidas pelo experimentador, o tamanho dos optotipos é gradativamente diminuído (os detalhes se 
tornam mais finos) até que o paciente não consiga resolver os detalhes do optotipo, determinando a maior capacidade de resolução do sistema visual (Schwartz, 2004).

A notação usualmente utilizada na medida da acuidade visual por optotipos é a fração de Snellen. Nesta maneira de se expressar a acuidade visual o numerador indica o optotipo visto e a denominador indica a distância em que uma pessoa normal resolve o optotipo. Assim uma fração de 20/20 indica que o sujeito resolve optotipos de 1 grau de ângulo visual a 20 pés quando um sujeito normal resolve também a 20 pés, indicando uma visão normal; uma acuidade de $20 / 40$ indica que o sujeito resolveu o optotipo a 20 pés enquanto que um sujeito normal resolve a 40 pés (Schwartz, 2004) (Figura 3).

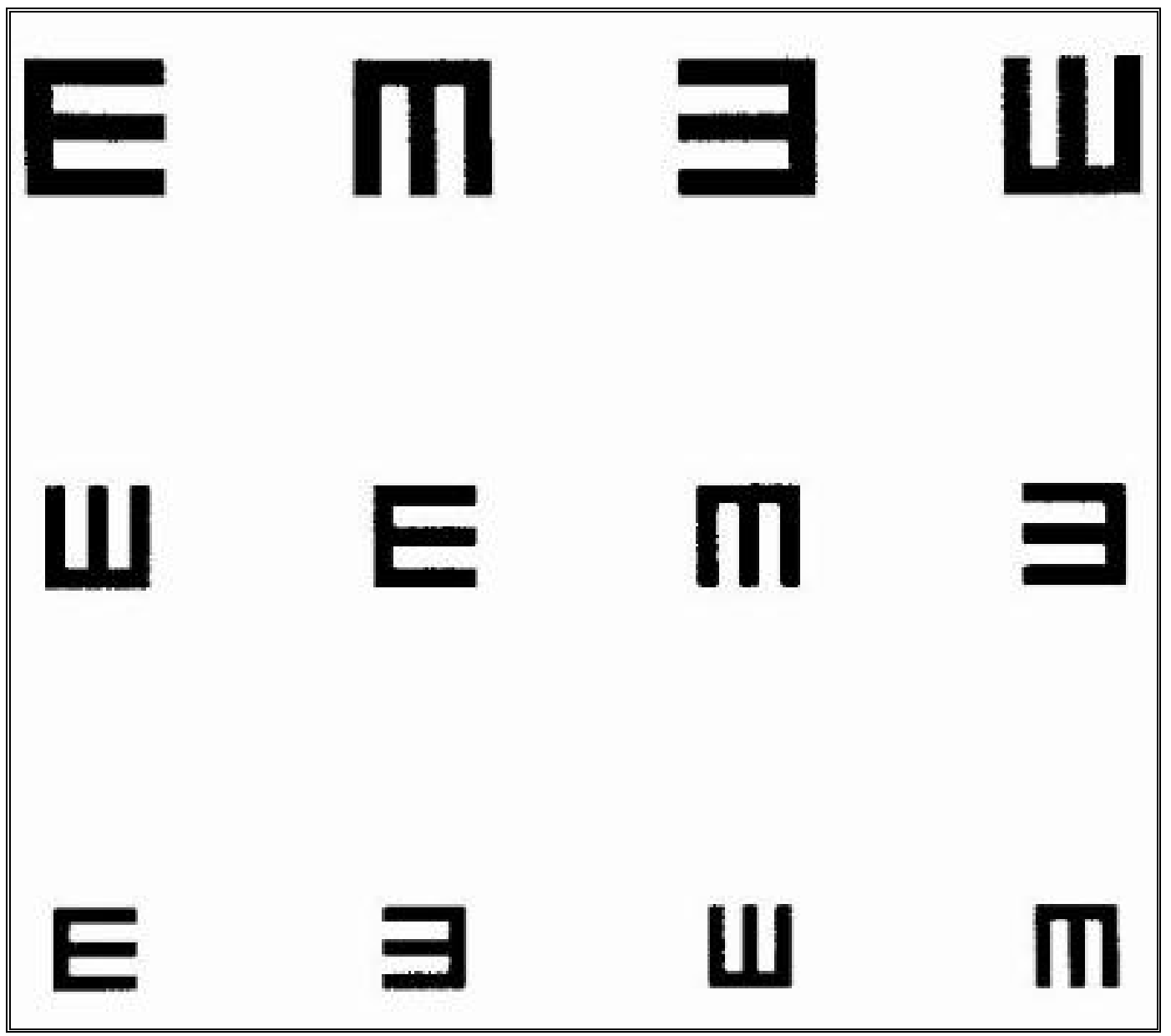

Figura 3: Tabela de Snellen. http://webvision.med.utah.edu/kallSpatial.html. 
Dentro da definição geral, podem-se considerar diferentes tipos de acuidade visual: a) - mínimo visível: detecção da presença de um estímulo visual, ou seja, o menor estímulo capaz de ser visto por um determinado sujeito; b) - $\underline{\text { mínimo resolvível ou acuidade visual }}$ comum: menor distância necessária entre dois estímulos para que sejam vistos como distintos. Este limite de resolução é freqüentemente expresso em grau de ângulo visual e designado Mínimo Ângulo de Resolução (MAR); c) - mínimo discriminável ou hiperacuidade: limiar espacial muito menor que a acuidade visual, ou das tarefas localizadas de um elemento em relação ao outro (acuidade Vernier) (Westheimer, 1992).

Para crianças pré-verbais e indivíduos não verbais, como crianças e adultos com alterações físicas ou mentais, à acuidade de resolução é a medida mais frequentemente realizada, pois sua metodologia se baseia na habilidade em resolver padrões listrados ou em forma de tabuleiros de xadrez. Dentre os métodos mais usados para avaliação da acuidade visual de resolução, dois são comportamentais, o nistagno optocinético e o olhar preferencial; e com os métodos eletrofisiológicos, o potencial visual evocado.

As primeiras tentativas de quantificação das respostas perceptuais e sensoriais basearam-se na habilidade das crianças em detectar listras num tambor giratório de nistagno optocinético, observando a presença de nistagno ou sua ausência durante a movimentação repetitiva de padrões de grade com largura de listras cada vez menores (maior freqüência espacial) (Gorman; Cogan; Gellis, 1957). A largura de grade mais fina que provocasse o nistagno determinaria a acuidade visual. Esta resposta de provocação do nistagno é involuntária e presente em recém-nascidos (Hamer; Mayer, 1994).

Posteriormente, a partir da década de 70, surgiram novas técnicas para avaliação da acuidade visual, incluindo-se o método do olhar preferencial e os potenciais visuais 
evocados. A resposta do olhar preferencial foi descrita por Fantz (1958) durante estudos sobre a discriminação de lactentes a diversos estímulos visuais e, a partir daí, foram descritas técnicas do olhar preferencial de escolha forçada e suas variantes. Atualmente, a técnica mais utilizada baseada no olhar preferencial é a dos cartões de acuidade de Teller (Dobson; Mayer; Lee, 1990, Macdonald et al. 1985).

A acuidade de Teller consiste na apresentação de estímulos de grade (listras brancas e pretas) de onda quadrada de alto contraste, pareados com um estímulo cinza homogêneo de mesma luminância média. Por um orifício central nos cartões, o observador, que desconhece a localização e a freqüência espacial da grade, faz um julgamento pelo padrão de resposta do sujeito. A acuidade visual é definida como a freqüência espacial correta que foi julgada corretamente em $75 \%$ das vezes. Os valores normativos, que classificam a acuidade como dentro ou fora dos limites de normalidade estão disponíveis em estudos populacionais (Woodhouse et al, 1992; Mayer et al, 1995; Salomão; Ventura 1995).

\subsection{POTENCIAL VISUAL EVOCADO (PVE)}

O Potencial Visual Evocado (PVE) representa uma parte da atividade do córtex visual em resposta à informação visual, que passa pelo sistema óptico do olho e é processada pela retina, principalmente na mácula, e pela via genículo-estriada. Clinicamente os PVEs são registrados a partir de eletrodos colocados no couro cabeludo sobre a região do lobo occipital e podem ser utilizados como um teste de função visual não dependente da 
resposta verbal do individuo testado (Norcia; Tyler 1985b; Furuskog; Wanger 1986; Hamer et al. 1989; Skarf 1989; Gottlob et al. 1990).

A presença de uma resposta visual evocada indica que a via visual resolveu a informação do estímulo até o ponto no sistema visual onde a resposta é gerada (Norcia e Tyler, 1985b), ou seja, até o lobo occipital. Três tipos de estímulo são comumente usados: flash de luz, padrão reverso e padrão de aparece-desaparece (Harding et al, 1996).

Em humanos, o PVE tem sido utilizado para a avaliação da acuidade visual de resolução, principalmente em recém-nascidos e crianças. Sokol (1978), utilizando PVEs de padrão reverso em bebês normais, observou que a acuidade visual melhorava de 20/150 aos dois meses de vida, para o valor de 20/20 por volta do sexto ao oitavo mês de vida. Quando esta mesma avaliação foi realizada com métodos comportamentais os valores de acuidade variam de 20/600 a 20/400 ao nascimento a 20/20 entre 36 e 60 meses de idade (Courage e Adams, 1990; Birch e Connor, 1991).

Devido aos PVEs representarem uma resposta neural, não sendo necessária uma resposta verbal ou motora, para algumas condições e patologias ele apresenta uma vantagem sobre as medidas obtidas comportamentalmente, já que não há limites de idade para ser realizado e necessita-se de um mínimo de colaboração para a realização do exame.

Em um estudo realizado por Dobson e Mayer (1990) avaliando os sujeitos por dois métodos comportamentais e pelos PVEs de padrão reverso, observou-se que nas avaliações pelos três métodos houve um aumento proporcional no valor médio da acuidade visual entre o nascimento e o sexto mês de vida, o que sugere a validade das três técnicas. 


\subsubsection{POTENCIAL VISUAL EVOCADO DE VARREDURA}

Embora os PVEs de padrão reverso sejam utilizados na prática clínica, a grande dificuldade para algumas faixa etárias é o longo tempo necessário para registrar respostas suficientes e gerar medidas confiáveis da acuidade visual. Com o desenvolvimento da técnica dos potenciais visuais de varredura de freqüência espaciais (PVEV), houve uma redução significativa no tempo de testagem (Tyler et al. 1979; Norcia; Tyler, 1985b). Neste método, utiliza-se, como estímulo visual, padrões listrados (grades de ondas quadradas ou senóides), brancas e pretas com contraste alto e constante que revertem em polaridade, isto é, as listras brancas tornam-se pretas e vice-versa. Durante a testagem, que tem um tempo total de 10 segundos, os padrões são modificados a cada segundo. Desta maneira, 10 estímulos de tamanhos diferentes são apresentados nos 10 segundos da varredura.

A atenção do indivíduo que está sendo testada é mantida mais facilmente num estado constante durante um período de 10 segundos, ao contrário do maior tempo exigido pelos outros métodos. Portanto, os PVEVs têm sido utilizados para medida da acuidade visual mono e binocular em recém-nascidos e lactentes, incluindo aqueles nascidos prematuramente (Norcia et al. 1985b; Hamer et al. 1989, Oliveira, et al. 2004).

Estudos realizados indicam que os PVEVs podem fornecer estimativas da acuidade visual que se relacionam com a acuidade de optotipos e com os achados clínicos tanto em crianças normais, como em crianças portadoras de alterações neurológicas e/ou portadoras de patologias visuais, como estrabismo, retinopatia da prematuridade e atrofia óptica, entre outras (Norcia et al. 1987; Gottlob et al. 1990; Katsumi et al. 1996; Salomão; Birch 1996; Salomão et al. 2000; Costa 2001; Oliveira, et al. 2004). 


\subsection{COMPLICAÇÕES VISUAIS NA HIDROCEFALIA}

Há uma série de trabalhos que acompanham as alterações oftalmológicas e visuais associadas com a hidrocefalia, porém não foram encontrados na literatura estudos prospectivos, que avaliem o desempenho visual em testes de crianças com hidrocefalia comparando-se o tempo de derivação.

Tzekov C. et al (1991) em seu estudo realizado com 75 crianças em idade escolar e com diagnóstico de hidrocefalia tratadas cirurgicamente, com ou sem Mielo mostraram que a AV binocular estava diminuída em quase $50 \%$ da amostra e que as crianças com hidrocefalia e Mielo foram menos comprometidas às crianças sem diagnóstico de Mielo. Os autores citam que esta melhora poderia ser pelo tempo entre diagnóstico e DVP ou número de revisões cirúrgicas realizadas para controle da DVP, porém não há correlação destes dados em resultados.

Cushing et al (1990) enfatizaram a importância da dilatação do terceiro ventrículo como compressão mecânica e força de distorção da via visual. A expansão do terceiro ventrículo pressiona o infundíbulo (formação nervosa que tem o papel de sustentar a hipófise, se localiza no assoalho do III ventrículo) para baixo e sua via comprime o ângulo posterior do quiasma óptico, podendo levar a alterações visuais como defeitos no campo visual.

Tzekov et al. (1991), avaliaram os sintomas neuro-oftalmológicos em 126 crianças tratadas com DVP. As crianças foram avaliadas no pré-operatório. Os dados afirmam que há uma incidência alta de distúrbios neuro-oftalmológicos visuais como sinal do sol poente, 
síndrome do aqueduto de sylvius, paresia do nervo crânio cerebral, nistagmo e atrofia óptica antes da realização da cirurgia. Os autores confirmam que os sinais neurooftalmológicos muitas vezes precedem as manifestações da Tomografia de Crânio e por isso, podem ser determinantes em diagnósticos precoces de complicações da DVP.

De fato, a mudança da função visual muitas vezes precede as manifestações em exames de neuroimagem, como a Tomografia Computadorizada (CT), determinando sua significância para o diagnóstico precoce de complicações no sistema de derivação.

Heikkinen; Mustonen, (1987), com o objetivo de avaliar as alterações neurológicas de 76 crianças com HIC, verificaram que 29 crianças apresentaram uma média de 3 revisões cirúrgicas para DVP por paciente. Desses pacientes somente 15 apresentaram uma resposta neurológica normal, os demais apresentaram respostas neurológicas alteradas. A AV reduzida estava relacionada com os grupos que necessitou de um maior número de revisões cirúrgicas (29 crianças). Entretanto, uma falha deste trabalho é que os autores não definem quais foram os parâmetros utilizados para a classificação da AV reduzida.

Dennis et al. (1989) sugerem que os distúrbios da AV e motilidade visual resultam no déficit de desenvolvimento do córtex visual e conseqüentemente influenciam a inteligência não verbal nos pacientes com diagnóstico de hidrocefalia devido ao desajuste visuoespacial e visuomotor.

Gaston, 1989, realizou um estudo retrospectivo para avaliar a incidência de complicações oftalmológicas em 322 crianças com diagnóstico de Mielo. Os autores concluem que somente $27 \%$ da amostra apresentaram função visual normal. Das crianças que apresentaram algum déficit ocular como papiloedema, nistagmo e atrofia óptica, a 
revisão da DVP foi essencial para a melhora dos sintomas, mas não restaurou a motilidade visual normal e função visual. Os autores concluem que a melhor estratégia para prevenir complicações oculares, melhorar a qualidade de vida e aumentar a sobrevida é realizar consultas oftalmológicas de rotina. Porém, ainda assim não foram encontrados trabalhos prospectivos na literatura que comparam os distúrbios da acuidade visual com o tempo da derivação. 
2.0 OBJETIVOS 


\subsection{OBJETIVOS}

Poucos trabalhos estudam a função da acuidade visual e o seu desenvolvimento em crianças com hidrocefalia de diferentes etiologias com diferentes formas de tratamento. Portanto, o presente estudo tem como objetivos:

a) verificar a eficácia do método e medir a acuidade visual em crianças de zero a 5 anos com diagnóstico de hidrocefalia, derivada ou não.

b) verificar a influência dos diferentes fatores etiológicos da hidrocefalia na acuidade visual. (tempo da derivação, etiologia, complicações, números de derivações, idade gestacional).

c) determinar se há ou não influência do tempo da derivação na acuidade visual das crianças com hidrocefalia. 
3.0 MÉTODOS 


\subsection{MÉTODOS}

\subsection{CASUÍSTICAS}

O presente estudo foi aprovado pelo Comitê de Ética em Pesquisa (anexo 1, pag.93) e trata-se de uma coorte prospectiva de 55 pacientes encaminhados para a avaliação de acuidade visual realizada no Laboratório de Eletrofisiologia e Psicofísica Visual Clínica do Departamento de Psicologia Experimental do Instituto de Psicologia da Universidade de São Paulo.

\subsection{CRITÉRIOS DE INCLUSÃO}

Os critérios de inclusão para a pesquisa foram os seguintes:

a) crianças de o a 6 anos incompletos;

b) crianças com diagnóstico de hidrocefalia derivada ou não, decorrente de hemorragia intracraniana, mielomeningocele ou de etiologia congênita;

c) crianças cujos responsáveis legais concordaram em participar do estudo assinando o termo de Consentimento Livre e Esclarecido (anexo 2, pag. 94). 
Foram excluídas do estudo crianças com hidrocefalia derivadas ou não, com etiologias diversas daquelas citadas nos critérios de inclusão; crianças maiores que seis anos, crianças cujos responsáveis legais não aceitaram o termo de consentimento; crianças que não apresentavam condições de aplicação do teste de acuidade visual.

\subsection{MEDIDA DA ACUIDADE VISUAL DE RESOLUÇÃO DE GRADES}

Para esta medida, utilizou-se o método dos PVEVs proposto por Tyler et al. (1979) e Norcia; Tyler (1985b). Todos os exames foram realizados no Setor de Eletrofisiologia e Psicofísica Visual Clínica do Departamento de Psicologia Experimental do Instituto de Psicologia da Universidade de São Paulo. Os pacientes foram sentados confortavelmente no colo de um de seus pais ou acompanhantes e permaneceram a uma distância de 50 a 80 centímetros $(\mathrm{cm})$ do monitor. As respostas foram obtidas binocularmente a partir dos eletrodos de eletroencefalograma (Grass Gold Disc Electrodes - E6GH) posicionados no couro cabeludo. As crianças utilizaram uma faixa elástica para fixar estes eletrodos. Os PVEVs foram registrados a partir de duas colocações bipolares de eletrodos (01 e 02), 2-3 $\mathrm{cm}$ à esquerda e à direita de um eletrodo de referência comum (oz) colocado a $1 \mathrm{~cm}$ acima do ínion, na linha mediana. O eletrodo Terra foi colocado $2-3 \mathrm{~cm}$ acima do eletrodo de referência seguindo os padrões sugeridos pela Sociedade Internacional para Eletrofisiologia da Visão (ISCEV, 1995) e o estímulo foi apresentado no monitor por 10 segundos (Figura 4). 


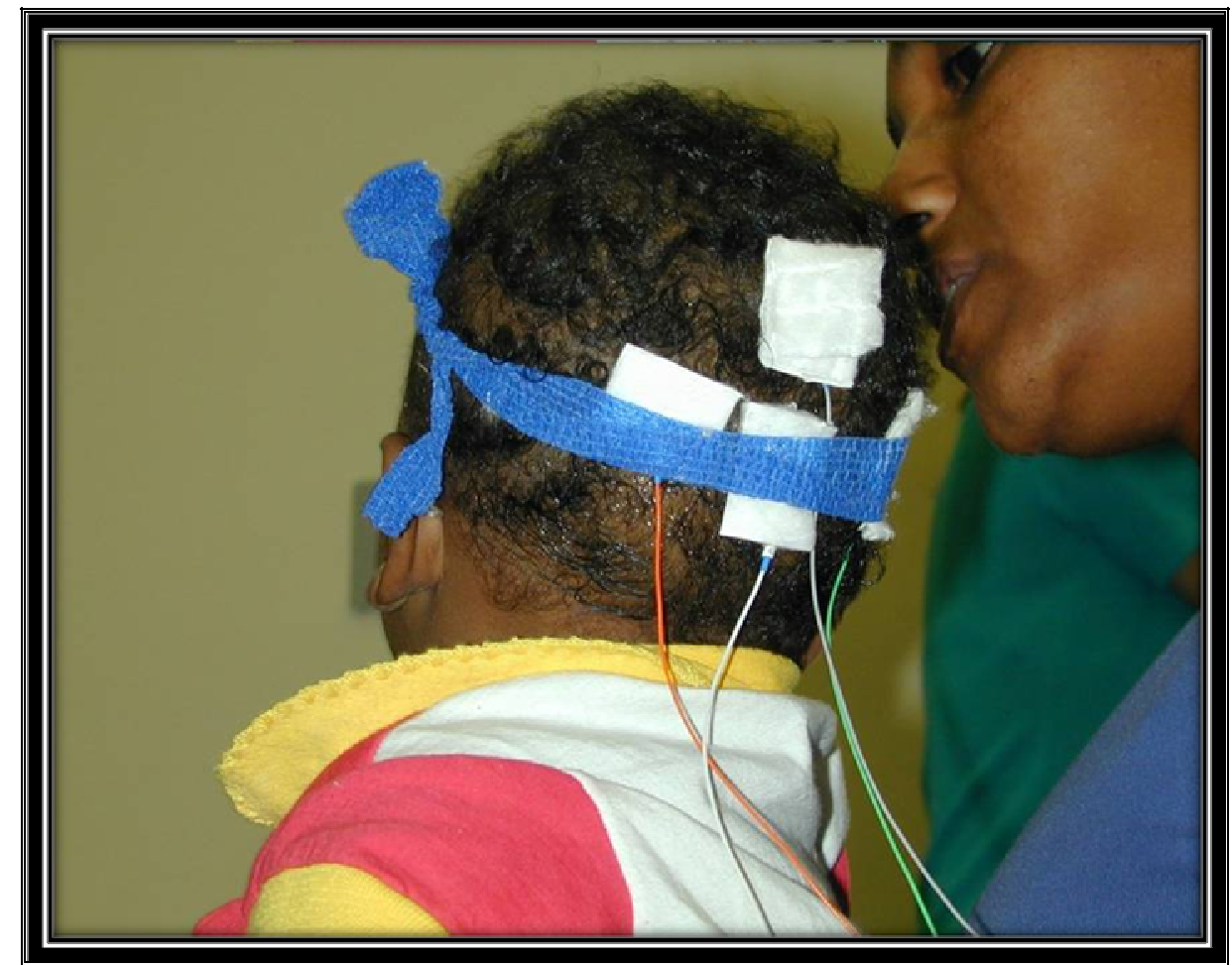

Figura 4: Posicionamento dos eletrodos na região cefálica.

Com a sala escura e o monitor ligado, a atenção das crianças foi atraída para a tela do monitor por pequenos brinquedos que foram apresentados 1-2 $\mathrm{cm}$ em frente à tela durante os 10 segundos de cada registro. O experimentador julgou se a criança estava ou não fixando o brinquedo, pelo reflexo do monitor no centro da pupila. Os brinquedos, cujos tamanhos eram desprezíveis, por terem freqüências espaciais diferentes e não acompanharem a freqüência de reversão do estímulo, não interferiu na medida da acuidade visual. Caso a criança mudasse de direção do olhar ou ocorresse interferência na captação do registro, o experimentador interrompia ou anulava o registro até ocorrer nova fixação (Figura 5). 


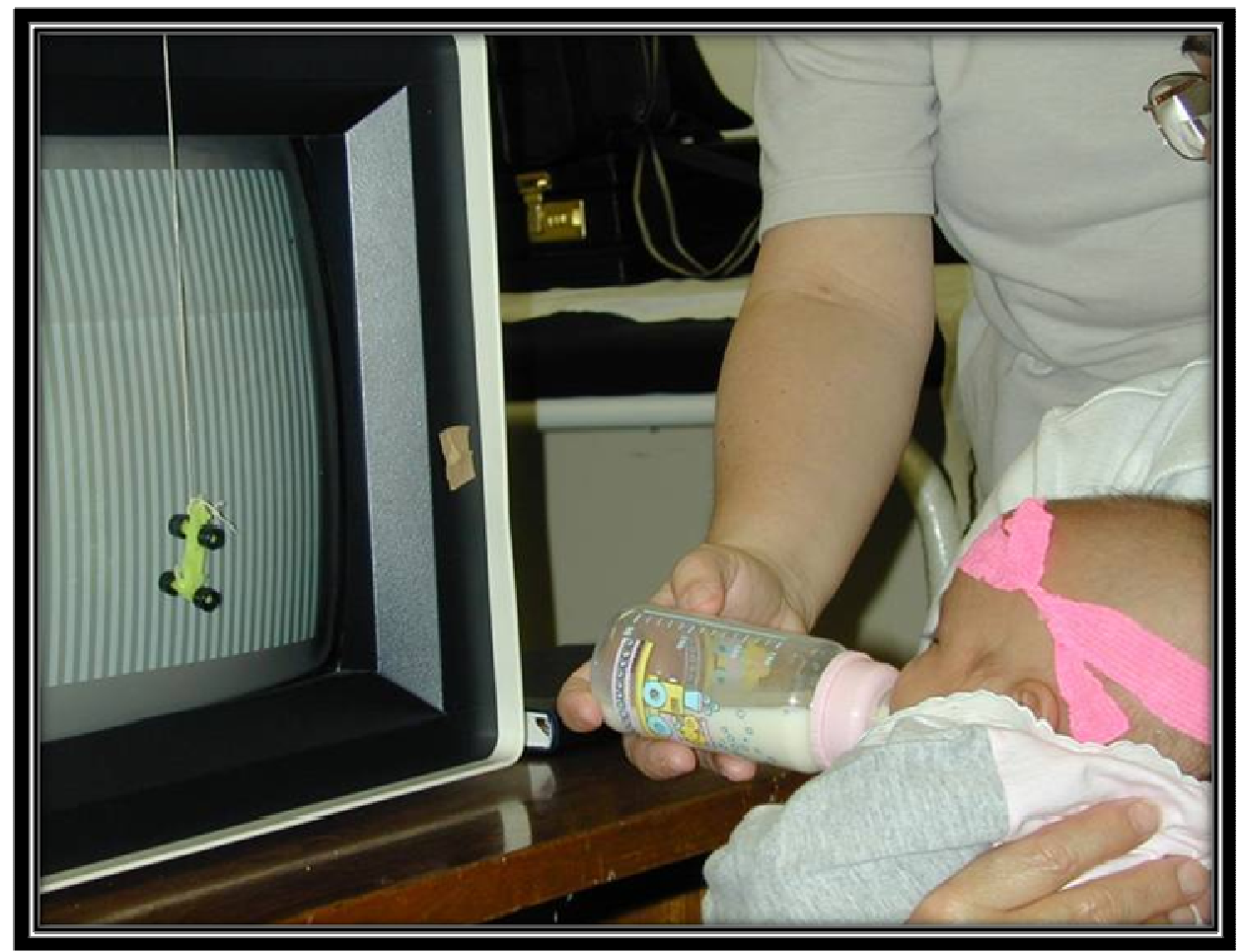

Figura 5: Estímulo de grades apresentado para a criança

\subsubsection{EQUIPAMENTO DE REGISTROS}

O sistema de gravação consistiu de um módulo de interface e um microcomputador Power Macintosh modelo 7100/66. O NUDIVA (Digital Infant Visual Assessment) software desenvolvido por Christopher Tyler e Anthony Norcia (1985) na Smith Kettlewell Eye Research Foundation em São Francisco - USA, foi o sistema utilizado para se obter os dados dos PVEVs. O potencial visual evocado foi amplificado por Neurodata Aquisition System Model $12 \mathrm{C}-4-23$ da Grass Instrument Company. Para todos os sujeitos avaliados, foi utilizado um ganho de 10.000 vezes com filtros de freqüência em 1 e 100 hertz (HZ), com corte em -3 decibéis $(\mathrm{dB})$. Uma transformada discreta de Fourier foi aplicada aos dados do PVE para se medir a amplitude e a fase sobre uma faixa de $1 \mathrm{~Hz}$ centralizada no segundo harmônico a 6 reversões por segundo. 


\subsubsection{MONITOR}

Grades verticais de onda quadrada a uma freqüência de 6 reversões por segundo foram apresentadas em um monitor de vídeo monocromático Dotronix modelo EM 2400 D 788 com 16 polegadas a 55cm. A luminância média foi de 159 candelas por metro quadrado. O monitor manteve o contraste constante durante toda a avaliação, sendo ajustado para não produzir mudanças na luminância média correlacionado com o padrão reverso (flicker). A figura 6 representa de uma forma esquemática, o equipamento de registro e o monitor.

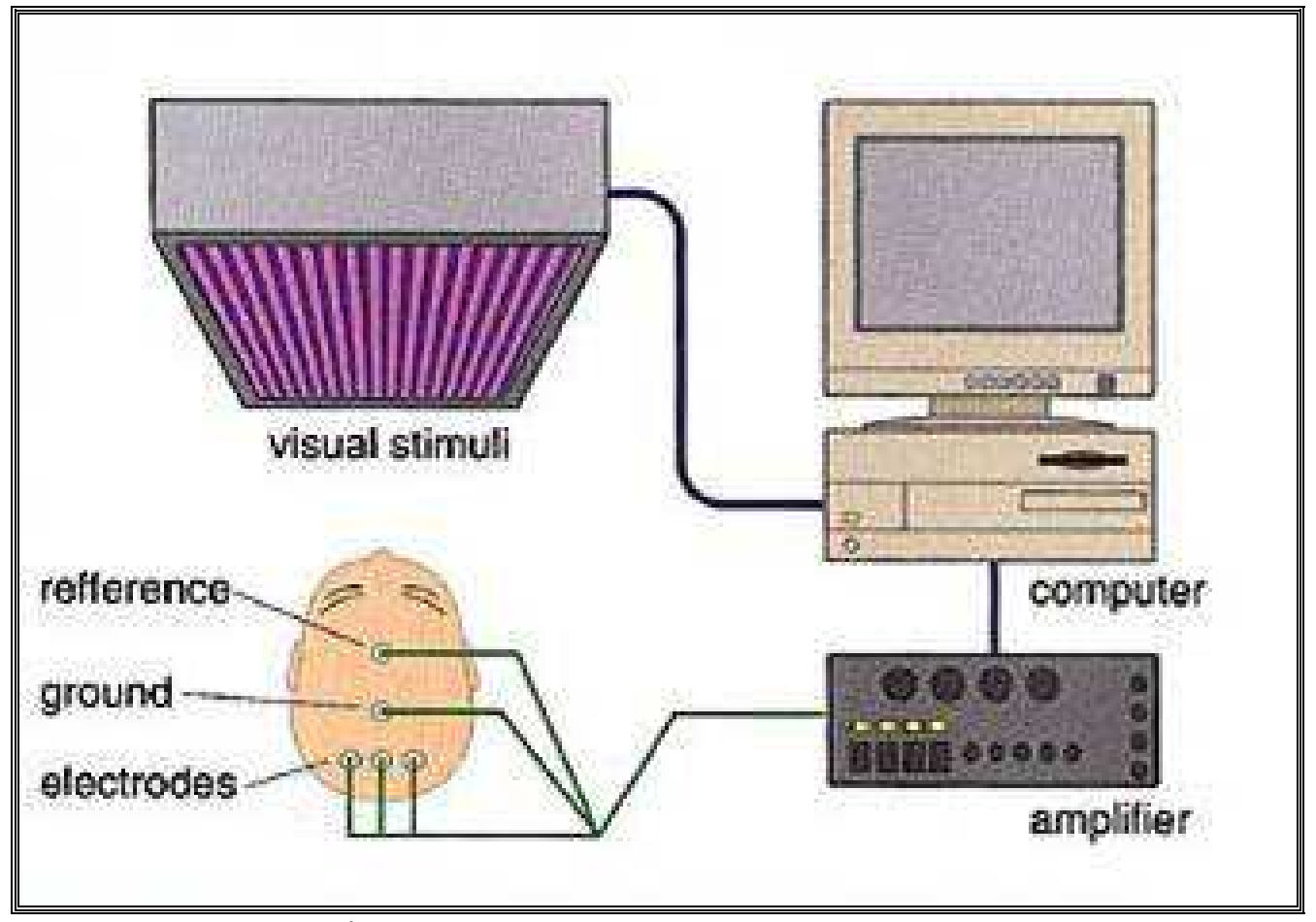

Figura 6: Desenho esquemático do Sistema utilizado para registro do PVE 
Três critérios foram utilizados para considerar um sinal como representativo do valor de resposta do potencial visual evocado:

1. A amplitude foi suficientemente grande em relação à média do ruído na freqüência auxiliar,

2. A fase da resposta deveria estar conforme certos critérios a serem discutidos e

3. Não poderia haver evidência de artefatos no local do valor de limite.

\subsubsection{CRITÉRIO DE REGISTRO PELA RELAÇÃO SINAL/RUÍDO}

Uma medida conveniente para se calcular à amplitude da resposta foi à relação sinal por ruído, que foi a amplitude presente em um nível contraste de resposta versus à amplitude presente durante o teste do nível contraste adjacente. A probabilidade de o ruído exceder uma relação sinal/ruído de 2:1 sobre a média durante os 10 segundos de avaliação foi de $4,5 \%$. Em uma relação de $3: 1$ a probabilidade de um sinal falso foi de $0,3 \%$ (Norcia, A. M. e Tyler, C. W., 1985b).

Um valor de sinal falso de 4,5\% foi utilizado como padrão nas avaliações individuais, enquanto o valor de $0,3 \%$ foi utilizado para a obtenção do valor médio final, uma vez que proporcionou um nível de proteção adequado para a média de múltiplas avaliações quando combinarmos com a consistência da fase (Figura 7, parte C). 


\subsubsection{CARACTERÍSTICA DA FASE DO POTENCIAL VISUAL EVOCADO}

Por definição, a fase de distribuição do ruído foi uniforme sobre o intervalo de o a $2 \pi$ (Norcia e Tyler, 1985b). Na pequena faixa de ruído que resulta da filtragem de Fourier do eletroencefalograma, a fase varia continuamente. Uma resposta evocada foi caracterizada por sua fase circular ou sua sincronização com o estímulo. Portanto, uma fase constante é inconsciente com o ruído, mas, é característica de uma resposta evocada.

Os valores da fase foram acumulados em módulos de $2 \pi$. Podendo oscilar de $-\pi$ a $+\pi$. Uma fase de contorno contínuo pode ser visualizada pelo deslocamento de um segmento do contorno da fase de $2 \pi$, havendo a combinação dos contornos Figura 7, parte B).

A fase de uma resposta evocada pode também progressivamente se atrasar com o aumento da freqüência espacial devido a mudanças na latência do sistema visual. Atrasos na fase foram indicados por um movimento para cima nos dados acumulados para as funções de sintonia dos potenciais.

\subsubsection{REJEIÇÃO DE ARTEFATOS}

Artefatos de eletroencefalograma tais como movimentos nos eletrodos, posição do dreno da derivação ventricular e atividade muscular produzem elevação no nível de ruído e no contraste do sinal, ao passo que a resposta evocada elevará só a freqüência da resposta. 
Se o espectro do eletroencefalograma é plano, a amplitude do eletroencefalograma em uma freqüência adjacente pode ser usada como um indicador do ruído de fundo na freqüência de resposta durante a avaliação (Norcia e Tyler, 1985). A resposta e as freqüências de ruídos são independentes na análise e devem ter a mesma amplitude média na ausência de um sinal (Figura 7, parte $A$ ).

A figura 7 resume os três critérios de registro para a detecção da resposta evocada.

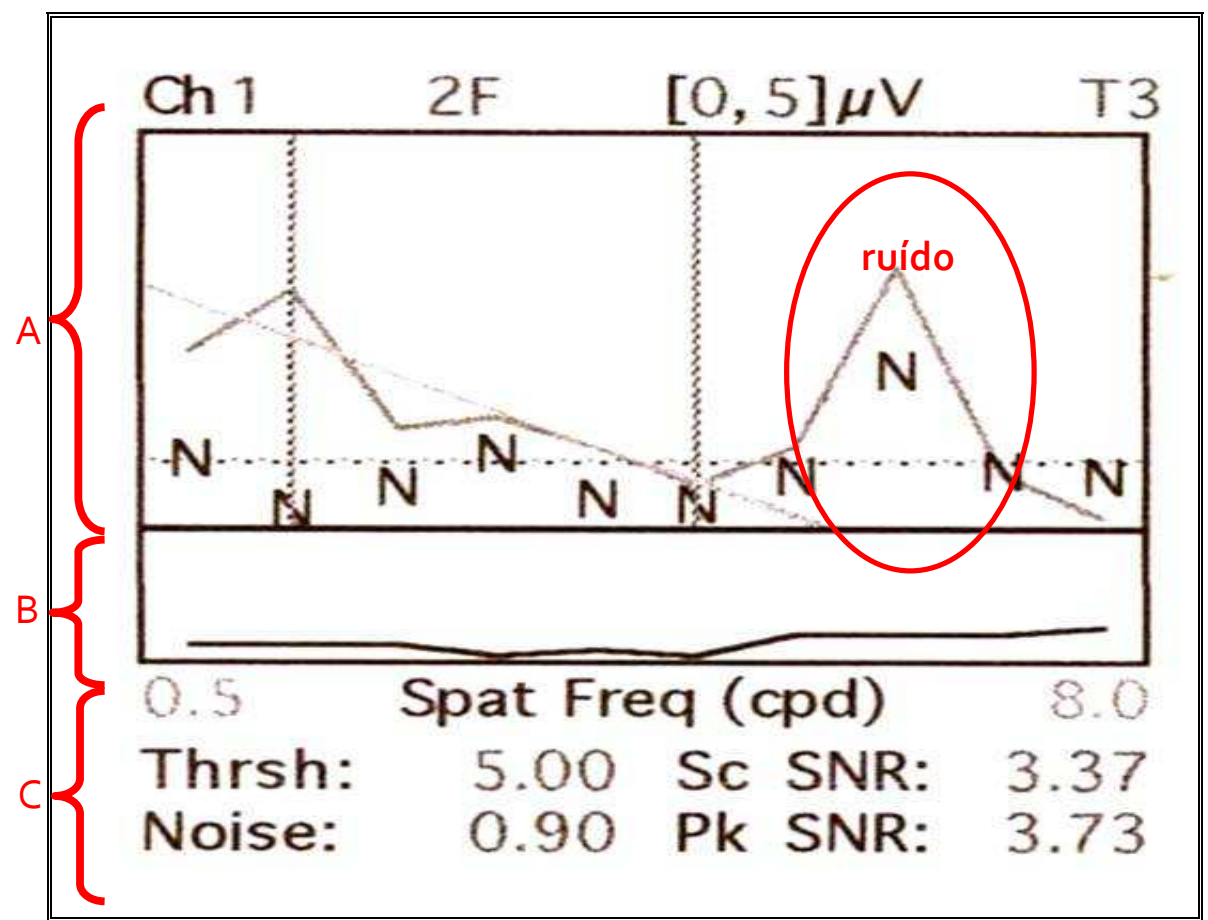

Figura 7: Registro de um resultado obtido na medida de AV. Chave A: Ordenadas: amplitude do segundo harmônico para cada uma das 10 freqüências espaciais representadas na abcissa interpolada por uma reta. $\mathrm{N}$ indica a amplitude do EEG em cada freqüência espacial, cuja amplitude média é representada pela linha pontilhada de varredura em 10 segundos. Chave B: fase de resposta relativa ao padrão temporal de estimulação. Chave C: SNR: relação sinal por ruído. 


\subsubsection{PROCEDIMENTO EXPERIMENTAL}

A acuidade de grades foi medida pela varredura de frequência espaciais num nível de contraste fixo (80\%). Dez freqüências espaciais linearmente espaçadas foram apresentadas, uma por segundo, iniciando-se pela frequência espacial mais baixa (listras largas). A amplitude da varredura foi selecionada pelo experimentador de acordo com a idade da criança, que poderia variar seu valor inicial e final de 0,25 a 25 ciclos por grau, conforme estudos normativos prévios (NORCIA 1985b) (Tabela 1).

\begin{tabular}{|c|c|}
\hline $\begin{array}{c}\text { IDADE } \\
\text { (semanas) }\end{array}$ & $\begin{array}{l}\text { FREQUÊNCIA INICIAL E } \\
\text { FINAL (ciclos por grau) }\end{array}$ \\
\hline $0-5$ & $0,25-5,0$ \\
\hline $6-10$ & $0,5-8$ \\
\hline $11-17$ & $1,0-10$ \\
\hline $18-24$ & $1,0-15$ \\
\hline $25-35$ & $1,0-20$ \\
\hline $36-51$ & $2,0-20$ \\
\hline $52-104$ & $2,0-25$ \\
\hline $6-10$ & $0,25-5,0$ \\
\hline $11-17$ & $0,5-8$ \\
\hline
\end{tabular}

O processamento da informação do EEG, pelo programa inclui a aplicação de uma transformada discreta de Fourier aos dados do PVEVs para se medir a amplitude e a fase sobre uma faixa de $1 \mathrm{~Hz}$ centralizada no segundo harmônico a 6 reversões por segundo.

Após a análise dos três critérios para considerar um sinal como representativo do valor de resposta do potencial visual evocado, a acuidade visual foi então estimada por um algoritmo automático por regressão linear, extrapolando-se, para amplitude zero, a parte 
descendente da reta e relacionando-se a amplitude do potencial visual evocado do segundo harmônico à freqüência linear. Quando a curva de regressão não foi calculada automaticamente, esta pode ser ajustada pelo próximo experimentador (Figura 8).

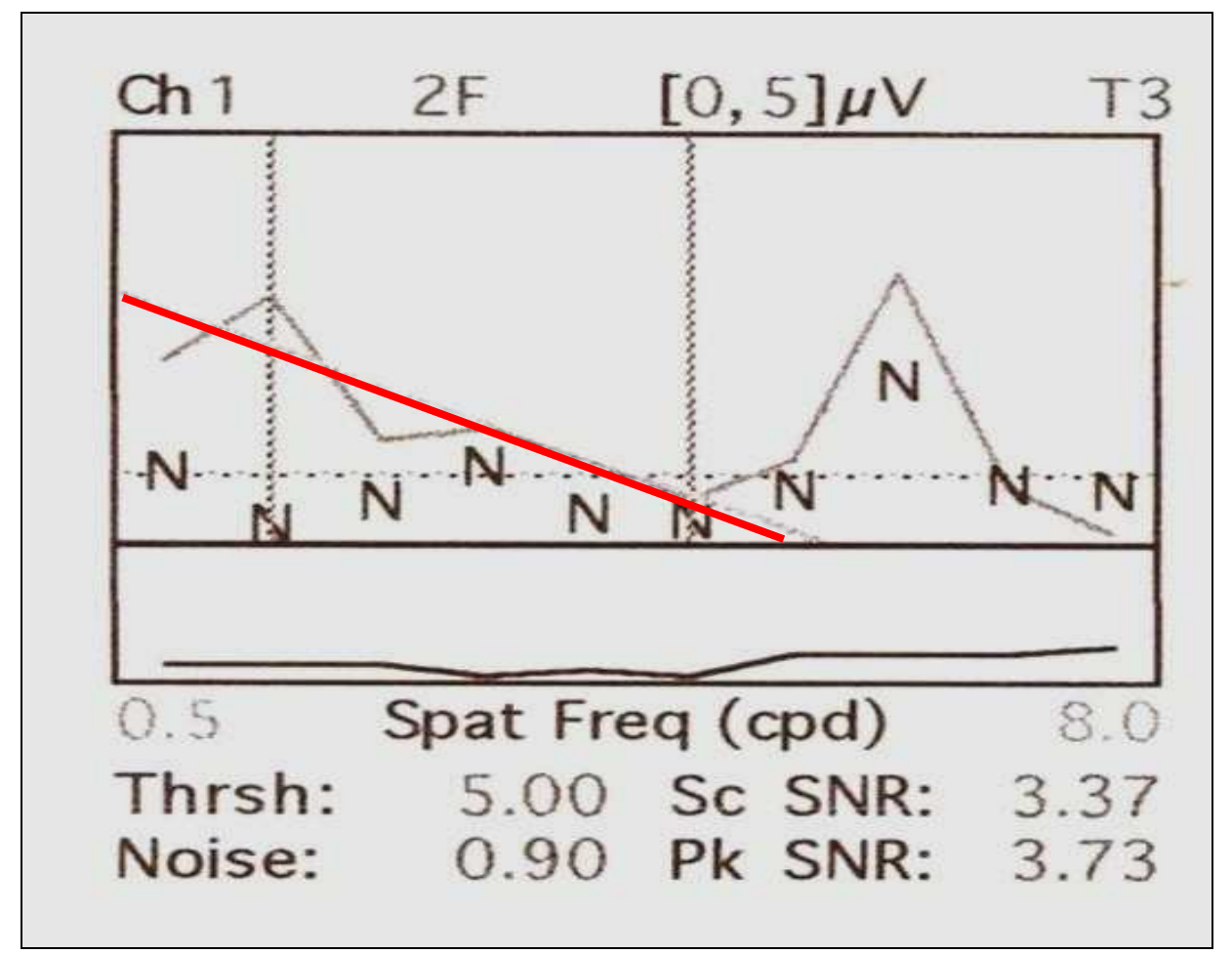

Figura 8: Registro real de avaliação dos registros obtidos. Linha vermelha representa a curva de regressão linear.

Em todos os casos foram obtidos dois limiares (um para cada canal), e o resultado final da acuidade foi calculado utilizando-se o maior valor de freqüência espacial (ciclos/grau). A acuidade da resolução mínima foi obtida por meio da transformação do valor limiar, expresso em ciclos por grau, no logaritmo de menor ângulo de resolução (logMAR) (NORCIA 1985b). Os valores da acuidade visual foram expressos em logaritmos na 
base 10, já que o desenvolvimento da acuidade visual em humanos segue progressão geométrica (Holladay 1997, Cruz; Salomão 1998).

O cálculo foi realizado pela seguinte operação:

$\log M A R=\log (30 / \mathrm{cpg})$

Onde log = logaritmo; 30 = número de ciclos em grau de ângulo visual e cpg = limiar obtido pelo PVEV e expresso em ciclos por grau (NORCIA e TYLER, 1985a).

Para a obtenção do valor equivalente à fração de Snellen (Snl = teste padrão na medida da acuidade visual), utilizou-se:

\section{$\mathrm{Snl}=$ anti-logMAR $\times 20$}

Onde anti-logMAR = anti-logaritmo do menor ângulo de resolução e 20 = distância em pés entre o estímulo e o indivíduo testado.

Para análise dos valores de AV em logMAR, utilizou-se a diferença entre o logMAR médio, da tabela de normalidades (Tabela 2) e o logMAR encontrado durante os exames (Anexo 3, pag.95). 
Tabela 2: Tabela de referência. Valores de referência para acuidade visual em logMAR e equivalentes em Snellen. (Fonte: NORCIA, 1985b)

\begin{tabular}{|c|c|c|c|c|}
\hline IDADE CORRIGIDA & MÍNIMO & MÍNIMO & MÉDIA & MÉDIA \\
\hline (m) & $\log M A R$ & Snellen & $\log M A R$ & Snellen \\
\hline o & 1,18 & $20 / 300$ & 0,93 & $20 / 170$ \\
\hline 1 & 1,10 & $20 / 250$ & 0,88 & $20 / 150$ \\
\hline 2 & 0,93 & $20 / 170$ & 0,7 & $20 / 100$ \\
\hline 3 & 0,88 & $20 / 150$ & 0,6 & $20 / 80$ \\
\hline 4 & 0,81 & $20 / 130$ & 0,54 & $20 / 70$ \\
\hline 5 & 0,78 & $20 / 120$ & 0,48 & $20 / 60$ \\
\hline $6-8$ & 0,65 & $20 / 90$ & 0,3 & $20 / 40$ \\
\hline $9-11$ & 0,60 & $20 / 80$ & 0,3 & $20 / 40$ \\
\hline $12-17$ & 0,48 & $20 / 60$ & 0,18 & $20 / 30$ \\
\hline $18-23$ & 0,35 & $20 / 45$ & 0,1 & $20 / 25$ \\
\hline \multirow[t]{2}{*}{$24-29$} & 0,24 & $20 / 35$ & 0,1 & $20 / 25$ \\
\hline & 0,18 & $20 / 30$ & 0 & $20 / 20$ \\
\hline
\end{tabular}

Para análise dos valores de AV em logMAR, utilizou-se a diferença entre o logMAR médio, da tabela de normalidades (Tabela 2) e o logMAR encontrado durante os exames (Anexo 3, pag. 95).

O cálculo da diferença entre os logaritmos (logMAR encontrado - logMAR esperado) foi aplicado para normatizar as idades entre os pacientes e facilitar a interpretação dos testes estatísticos, sendo assim, os valores negativos representam AV pior que a média e valores $\geq$ zero (o) representam, AV normal. Após está adaptação, utilizou-se o programa "Statistica 6.0" para análise dos resultados. O teste de Tukey foi aplicado para a 
identificação das associações entre as variáveis categóricas: derivação, complicação, etiologia, prematuridade e idade gestacional. Para a análise dos valores da AV nos diferentes grupos (etiologia, complicação, tempo de derivação) empregou-se a análise de variância (ANOVA); já para comparação entre os valores encontrados nos subgrupos (com derivação até 15 dias, com derivação $\geq 15$ dias e sem derivação) utilizou-se o teste de comparação entre retas com análise de regressão linear simples. O nível de rejeição para a hipótese de nulidade foi sempre fixado como $0.05(p<0.05)$. 
No período compreendido entre julho de 2004 e julho de 2006 preencheram os critérios de inclusão e não os de exclusão, 55 crianças com idade média de admissão ao protocolo de 74 semanas $( \pm 78,06)$, variando entre 2 e 291 semanas. A maior parte das crianças era do sexo feminino $(61,8 \%)$. O peso médio de nascimento dos recém nascidos foi de 2289,45 gramas $( \pm 1144,7)$ com variação de 675 a 4170 gramas, sendo que $54,5 \%$ foram considerados recém-nascidos de baixo peso por apresentarem peso de nascimento menor que 2500 gramas e $34,5 \%$ foram considerados de muito baixo peso por apresentarem peso de nascimento menor que 1500 gramas. A idade gestacional média ao nascimento foi de 34 semanas $( \pm 5,06)$, variando de 26 semanas a 40 semanas, sendo que 32 bebês foram classificados como prematuros (<37 semanas) e 23 classificados como recém nascidos de termo. A tabela 3 apresenta os dados demográficos da amostra do estudo. 
Tabela 3: Dados demográficos da casuística.

\begin{tabular}{lc}
\hline Variável * & Valores \\
\hline Id em sem.- $1^{\circ}$ exame (média \pm DP) & $74 \pm 78$ \\
Sexo Feminino n (\%) & $34(61,8 \%)$ \\
Peso Nascimento gramas (média \pm DP) & $2289,45 \pm 1144,71$ \\
Baixo Peso - $n(\%)$ & $30(54,5 \%)$ \\
Muito Baixo Peso - n (\%) & $19(34,5 \%)$ \\
Idade Gestacional sem (média \pm DP) & $34 \pm 5$ \\
Prematuro - $n(\%)$ & $32(58,2 \%)$ \\
Termo - $n(\%)$ & $23(41,8 \%)$ \\
Idade Corrigida sem - ${ }^{\circ}$ exame (média \pm DP) & $68 \pm 78$
\end{tabular}

*Id: idade: sem = semanas; DP = desvio padrão; $\mathrm{n}=$ números de casos; Idade Corrigida = Idade Real (40 semanas - Idade Gestacional).

Para a correta aplicação do teste de acuidade visual, através do PVE, é necessário proceder ao ajuste da idade gestacional normatizando todos os recém-nascidos prematuros como sendo de 40 semanas. Denominamos esta idade como, idade gestacional corrigida. Numericamente esta idade pode ser calculada a partir da seguinte expressão matemática:

$$
I d C=I d R-(40 \text { semanas }-I G) \text {, onde: }
$$

IdC = Idade Corrigida; IdR = Idade real no momento do exame; IG = Idade Gestacional 


\subsubsection{CARACTERÍSTICAS DA HIDROCEFALIA}

Conforme previsto nos critérios de inclusão, todos os pacientes apresentavam algum grau de hidrocefalia, confirmado através de métodos de imagem e avaliações neurocirúrgicas. O diagnóstico da hidrocefalia foi estabelecido em média no décimo sexto dia de vida, variando de zero dia a sessenta e oito dias (Anexo 3, pag. 95, coluna 5). Os diagnósticos etiológicos que levaram à hidrocefalia estão apresentados na Tabela 4. Neste aspecto, encontramos 25 pacientes com hidrocefalia decorrente de hemorragia intracraniana (HIC) no período neonatal; 20 crianças que apresentavam mielomeningocele (Mielo) e 10 bebês com hidrocefalia isolada e de causa congênita.

Tabela 4: Etiologia da Hidrocefalia

\begin{tabular}{lc}
\hline Etiologia da Hidrocefalia & $\mathrm{n}(\%)$ \\
\hline congênita & $10(18,2 \%)$ \\
mielomeningocele & $20(36,4 \%)$ \\
hemorragia intracraniana & $25(45,4 \%)$ \\
\hline Total & $55(100 \%)$ \\
\hline
\end{tabular}


A abordagem terapêutica da hidrocefalia na amostra estudada apresentou alguma variação quanto ao tipo de intervenção e quanto ao momento da intervenção. Neste sentido, dos 55 bebês avaliados, quarenta e cinco $(81,8 \%)$ foram submetidos à derivação ventrículo-peritoneal (DVP) ao passo que $10(18,2 \%)$ tiveram um manejo exclusivamente clínico. Naqueles submetidos à DVP, o tempo médio para a intervenção após o diagnóstico da hidrocefalia foi de 16 dias ( $\pm 21,79$ dias), variando de 1 dia à 121 dias. Estratificando, o tempo para a instalação da DVP e calculando o ponto de corte para tempo de derivação, conforme proposto por Fobe (1999) e Heinsenbergen (2002), verificamos que, trinta e uma crianças $(56,3 \%)$ tiveram o procedimento realizado com menos de 15 dias do diagnóstico de hidrocefalia enquanto que em 14 (25,4\%) a válvula foi instalada após 15 dias do diagnóstico e $10(18,1 \%)$ não foram derivadas. A tabela 5 demonstra as características da abordagem terapêutica. 
Tabela 5: Características da abordagem terapêutica.

\begin{tabular}{|c|c|c|c|c|c|}
\hline Ident. & $\begin{array}{c}\text { IG } \\
\text { (sem.) }\end{array}$ & $\begin{array}{c}\mathrm{PN} \\
\text { (gramas) }\end{array}$ & Sexo & $\begin{array}{l}\text { Diag. Hidro } \\
\text { (dias) }\end{array}$ & $\begin{array}{c}1^{\circ} \text { Derivação } \\
\text { (dias após diag Hidro) }\end{array}$ \\
\hline 1 & 27 & 11120 & $\bar{F}$ & 30 & 30 \\
\hline 2 & 32 & 1620 & $\mathrm{~F}$ & 27 & 5 \\
\hline 3 & 28 & 980 & $\mathrm{~F}$ & 17 & 2 \\
\hline 4 & 33 & 1545 & $\mathrm{~F}$ & 7 & 2 \\
\hline 5 & 36 & 2040 & M & 10 & ND \\
\hline 6 & 31 & 1470 & M & 5 & 2 \\
\hline 7 & 32 & 1150 & $\mathrm{~F}$ & 15 & 2 \\
\hline 8 & 38 & 3665 & M & 2 & 11 \\
\hline 9 & 33 & 2000 & $\mathrm{~F}$ & 7 & 12 \\
\hline 10 & 40 & 3340 & $\mathrm{~F}$ & 5 & 10 \\
\hline 11 & 37 & 2985 & M & 12 & 7 \\
\hline 12 & 40 & 3800 & $\mathrm{~F}$ & 0 & 9 \\
\hline 13 & 40 & 3925 & $M$ & 8 & 1 \\
\hline 14 & 28 & 1090 & M & 12 & 3 \\
\hline 15 & 40 & 2980 & M & 16 & ND \\
\hline 16 & 31 & 1020 & $\mathrm{~F}$ & 10 & 17 \\
\hline 17 & 31 & 960 & $\mathrm{~F}$ & 40 & 54 \\
\hline 18 & 40 & 2450 & $\mathrm{~F}$ & 0 & ND \\
\hline 19 & 40 & 3400 & $F$ & 3 & 4 \\
\hline 20 & 33 & 1860 & $\mathrm{~F}$ & 20 & 1 \\
\hline 21 & 30 & 3900 & $\mathrm{~F}$ & 0 & 1 \\
\hline 22 & 40 & 3250 & $M$ & 10 & 2 \\
\hline 23 & 40 & 3605 & $M$ & 68 & 45 \\
\hline 24 & 37 & 3380 & $\mathrm{~F}$ & 13 & 15 \\
\hline 25 & 28 & 740 & M & 35 & ND \\
\hline 26 & 32 & 1540 & M & 25 & ND \\
\hline 27 & 38 & 3220 & $\mathrm{~F}$ & 0 & 1 \\
\hline 28 & 39 & 3600 & M & 22 & ND \\
\hline 29 & 40 & 2950 & $\mathrm{M}$ & 0 & 60 \\
\hline 30 & 27 & 915 & $M$ & 15 & 36 \\
\hline 31 & 27 & 1100 & $F$ & 30 & 15 \\
\hline 32 & 27 & 1100 & $\mathrm{~F}$ & 45 & 5 \\
\hline 33 & 40 & 3250 & $M$ & 38 & 120 \\
\hline 34 & 40 & 3850 & F & 0 & 45 \\
\hline 35 & 40 & 3470 & $F$ & 60 & ND \\
\hline 36 & 28 & 675 & $\mathrm{~F}$ & 30 & ND \\
\hline 37 & 31 & 905 & M & 13 & 18 \\
\hline 38 & 32 & 1625 & $\mathrm{~F}$ & 0 & 4 \\
\hline 39 & 26 & 755 & $\mathrm{~F}$ & 38 & 13 \\
\hline 40 & 30 & 1520 & $\mathrm{~F}$ & 8 & 8 \\
\hline 41 & 39 & 2745 & $\mathrm{~F}$ & 30 & 5 \\
\hline 42 & 37 & 3120 & $M$ & 0 & 8 \\
\hline 43 & 36 & 2370 & $\mathrm{~F}$ & 4 & 1 \\
\hline 44 & 40 & 3900 & $M$ & 0 & 2 \\
\hline 45 & 40 & 2750 & $\mathrm{~F}$ & 0 & 19 \\
\hline 46 & 40 & 3330 & $\mathrm{~F}$ & 30 & 5 \\
\hline 47 & 36 & 3945 & $\mathrm{~F}$ & 9 & 5 \\
\hline 48 & 31 & 1075 & $M$ & 20 & 20 \\
\hline 49 & 35 & 1495 & $M$ & 10 & 7 \\
\hline 50 & 32 & 2190 & $\mathrm{~F}$ & 9 & 21 \\
\hline 51 & 26 & 790 & $M$ & 18 & ND \\
\hline 52 & 36 & 3250 & $\mathrm{~F}$ & 0 & ND \\
\hline 53 & 40 & 4170 & $\mathrm{~F}$ & 0 & 22 \\
\hline 54 & 27 & 1070 & $\mathrm{~F}$ & 4 & 39 \\
\hline 55 & 26 & 970 & $\mathrm{~F}$ & 24 & 17 \\
\hline Total 55 & 34 & 2289 & & 16 & 16 \\
\hline
\end{tabular}

* Linha azul = tempo de derivação $>15$ (total 14), linha verde = tempo de derivação $\leq 15$ (total 31) e linha branca $=$ não derivou (total 10). 
4.0 RESULTADOS 
4.0 RESULTADOS

4.1 TESTES DE ACUIDADE VISUAL

4.1.1 ADERÊNCIA ÀS AVALIAÇÕES DE ACUIDADE VISUAL

Das 55 crianças avaliadas no $1^{\circ}$ exame, 18 fizeram $02^{\circ}$ exame, 13 fizeram $03^{\circ}$ exame, 10 completaram quatro exames e apenas cinco completaram as cinco avaliações (Figura 9). Os motivos para a não realização dos cinco exames foram, na sua totalidade, o não comparecimento à consulta, sem justificativa. A média em dias entre os exames foi de 124.7 ( \pm 70.5 dias). Durante a realização da pesquisa, foram realizados 101 exames de Potencial Visual Evocado de Varredura em todos os pacientes estudados.

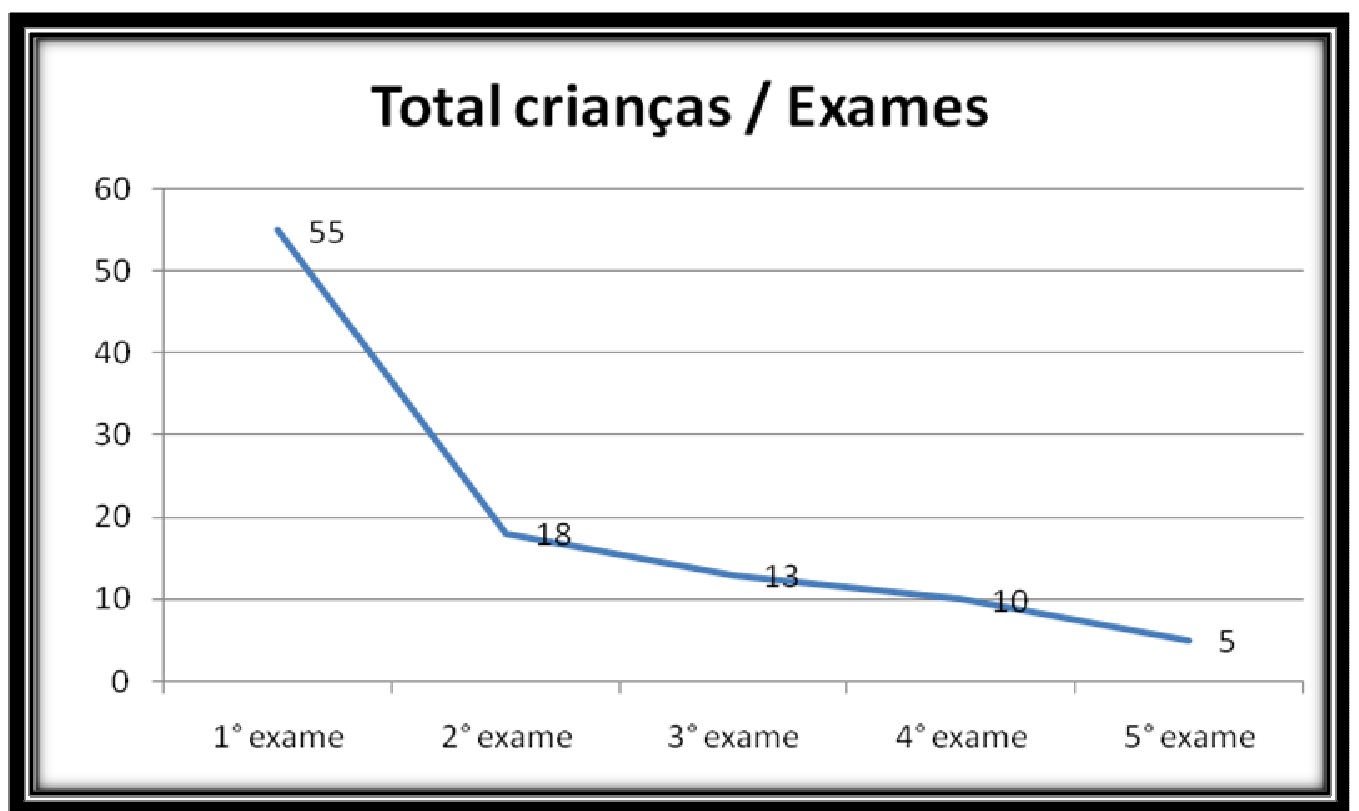

Figura 9: Freqüência dos pacientes durante os cinco exames realizados. Eixo $x$ representa o total de exames (5) e o eixo y representa o total de pacientes avaliados em cada exame, onde: $1^{\circ}$ exame $=55 ; 2^{\circ}$ exame $=18 ; 3^{\circ}$ exame $=13 ; 4^{\circ}$ exame $=10$ e $5^{\circ}$ exame $=5$ pacientes. 


\subsubsection{RESULTADO DOS TESTES DE ACUIDADE VISUAL NAS 5 AVALIAÇÕES}

Como descrito no item 3.6 pag. 50, foi usado um número, decorrente da diferença entre logMAR da tabela de referência (Tabela 2, pag. 52) e logMAR encontrado durante os exames (Anexo 3, pag. 95).

O número encontrado representa a diferença da AV das crianças do estudo em relação à tabela de normalidades, todavia, os números seguidos pelo sinal negativo (-) representam AV abaixo do esperado e os números seguidos pelo sinal positivo (+) ou números neutros (sem sinal), representam AV normal.

Considerando, portanto, a descrição acima, dentre as 101 avaliações de AV realizadas em todas as crianças durante $01^{\circ}$ exame, 95 exames (94\%) se mostraram alterados e seis (6\%) normais. Quando comparamos o número de exames normais ou alterados nas cinco avaliações intermitentes somente a $1^{\circ}$ e a $2^{\circ}$ avaliação apresentaram resultados normais (Figura 10). 


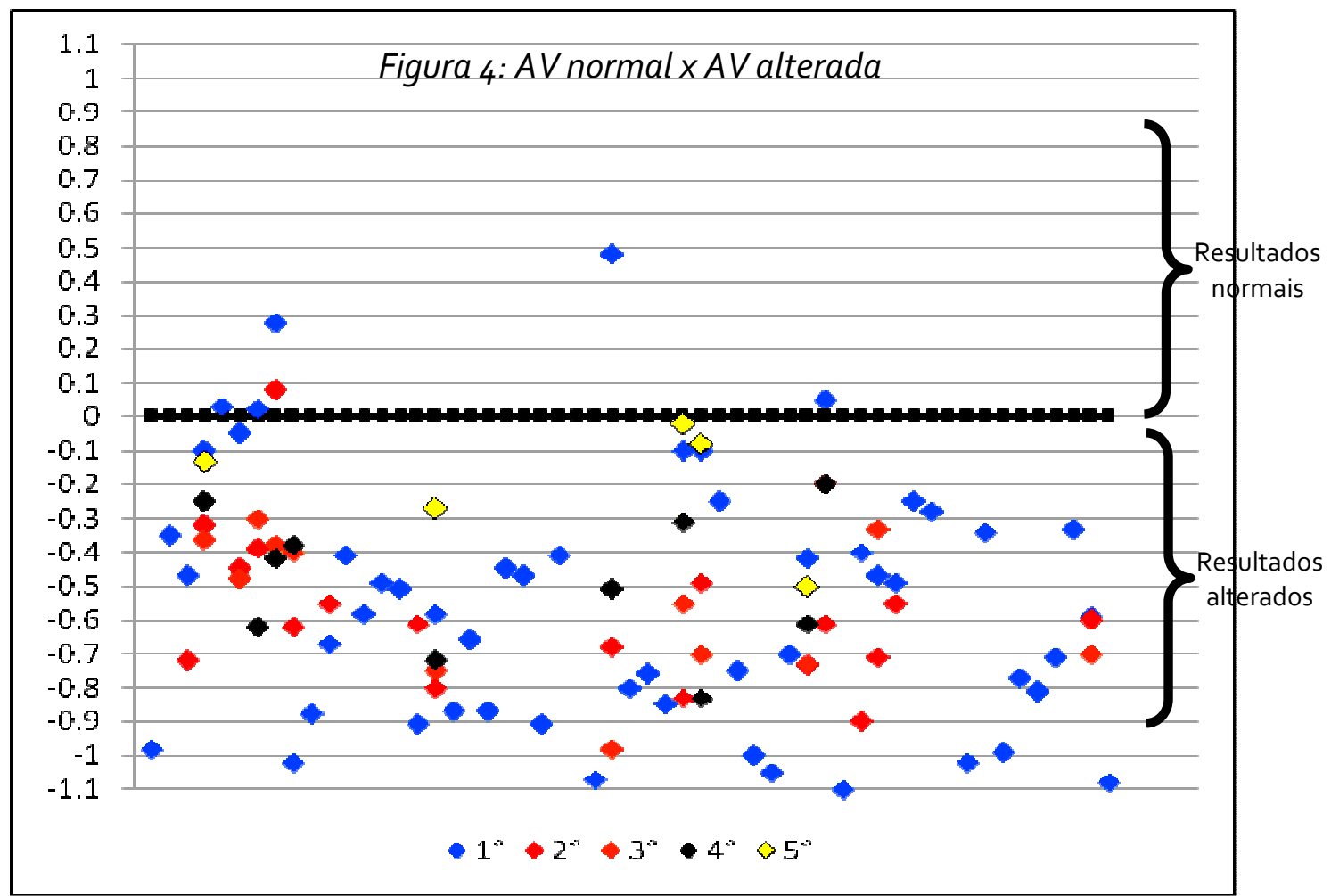

Figura 10: Total de avaliações realizadas durante o estudo, separados por grupos; Cada ponto no gráfico representa um exame realizado (total $=101$ exames): $1^{\circ}$ exame: azul, $2^{\circ}$ exame: vermelho; $3^{\circ}$ exame: laranja; $4^{\circ}$ exame: preto e $5^{\circ}$ exame: amarelo. Eixo das abscissas (linha preta) delimita os exames normais (eixo +, total: 6), sendo cinco avaliações no $1^{\circ}$ exame e uma avaliação no $2^{\circ}$ exame, e alterados (eixo -, total: 95$)$. Os exames subsequentes $\left(3^{\circ}, 4^{\circ}\right.$ e $\left.5^{\circ}\right)$ não apresentaram valores $\geq 0$.

\subsection{TEMPO DE DERIVAÇÃO}

Conforme descrito, no item 3.7.1 o tempo de derivação não foi homogêneo em nossa amostra e o ponto de corte foi de 15 dias. (Tabela 5, pag. 59).

A Figura 11 apresenta através de um gráfico de Box- Plot, os resultados da primeira avaliação da AV obtidos das 10 crianças com diagnóstico de hidrocefalia sem derivação (o); 31 crianças com tempo de derivação menor que 15 dias (1) e 14 crianças com tempo de derivação maior que 15 dias (2). A figura demonstra que não há diferença estatística $(p=$ o.699) entre a AV das crianças sem derivação comparando-se com as crianças com tempo 
de derivação maior que 15 dias, representadas no gráfico pelo Box-Plot o e 2, respectivamente. Houve diferença na $\mathrm{AV}$, todavia, quando comparamos as crianças, cujas derivações foram realizadas em até 15 dias do diagnóstico da hidrocefalia, com aquelas cuja derivação foi realizada após 15 dias $(p=0.038)$ ou com aquelas que não foram derivadas $(p=$ $0.031)$.

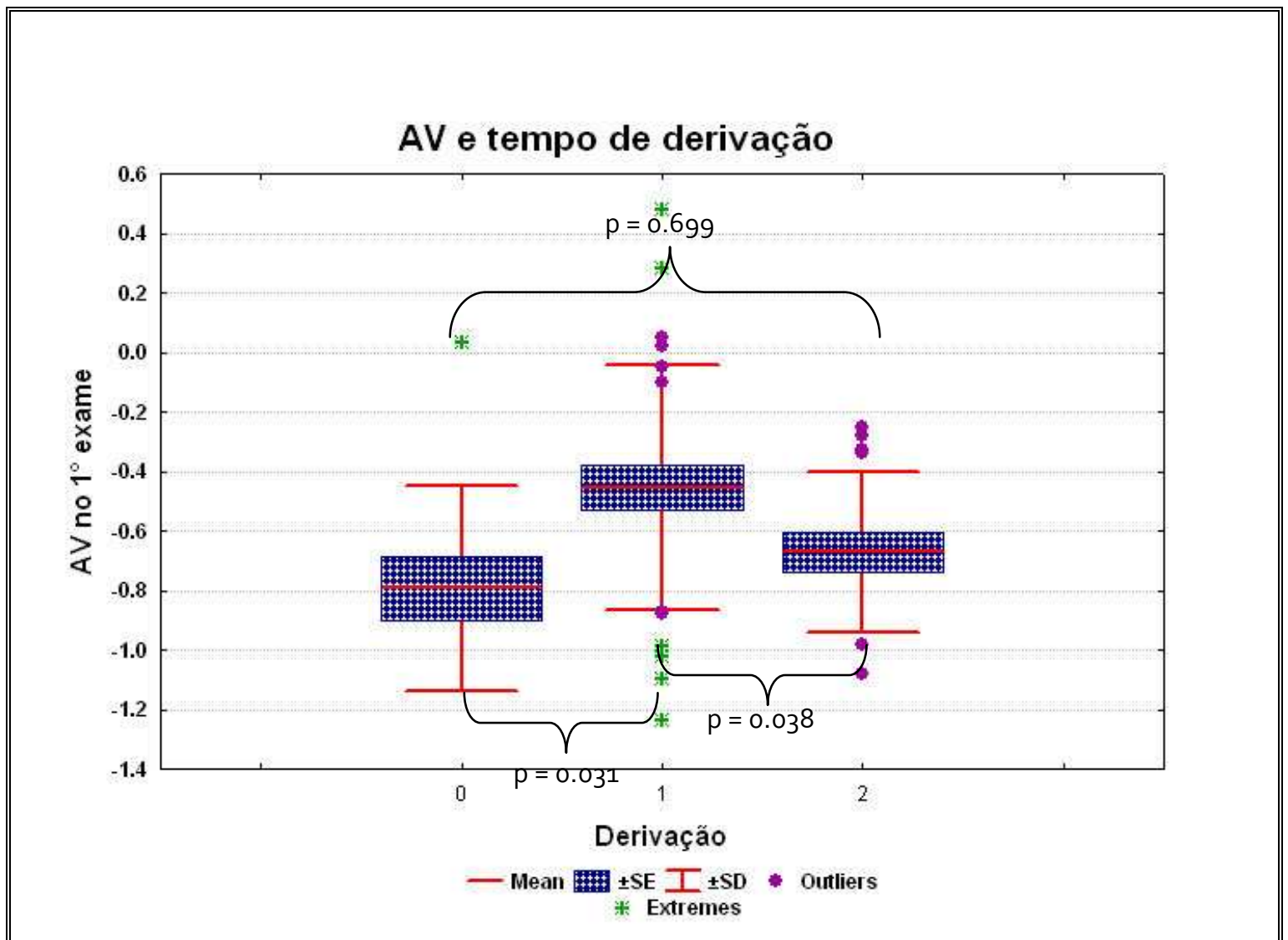

Figura 11: Comparação entre os grupos com diferentes tipos de intervenção, onde: o (10 crianças sem derivação), 1 (31 crianças com tempo de derivação $\leq 15)$ e 2 (14 crianças com tempo de derivação $\geq 15$ ). Os grupos o e 2 não apresentaram diferença estatísticas ( $p$ o.699); o grupo 1 apresentou diferença estatística quando comparado com o grupo o (p o.038) e 1 ( $p$ o.031). Análise de Variância (Teste de Tukey). 


\subsection{COMPLICAÇÕES NO $1^{\circ} \mathrm{E} 2^{\circ}$ EXAME}

Consideramos em nosso estudo, complicações qualquer intervenção cirúrgica e/ou medicamentosa para controle do sistema de DVP.

Um número considerável de crianças, da nossa amostra, apresentou algum tipo de complicação da hidrocefalia durante o transcorrer do estudo. As complicações encontradas estão apresentadas na tabela 6. Foi possível verificar que as intercorrências presentes foram: obstrução e infecção da válvula de DVP. Das 55 crianças estudadas apenas 45 foram derivadas e as complicações consideradas foram decorrentes da presença da DVP, portanto 37 crianças, das 45 possíveis, tiveram algum tipo de complicação. Dentre as complicações observadas, durante $01^{\circ}$ exame, verificamos que 36 foram obstrução e uma infecção que ocorreram de forma variada durante o período de estudo. Os dados relativos à complicação estão pormenorizados na tabela 6.

Tabela 6: Complicações encontradas nas 45 crianças com DVP.

\begin{tabular}{|c|c|c|c|}
\hline $\begin{array}{c}\text { Variável } \\
\text { Complicação }\end{array}$ & $\begin{array}{c}\mathrm{n}^{\circ} \mathrm{de} \\
\text { crianças }\end{array}$ & $\begin{array}{c}\text { derivação } \\
\leq 15 \mathrm{~d} />15 \mathrm{~d}\end{array}$ & $\begin{array}{c}\text { crianças com } \\
5 \text { exames }\end{array}$ \\
\hline obstrução & 36 & $24 / 12$ & 4 \\
\hline infecção & 1 & $1 / 0$ & 1 \\
\hline total & 37 & $25 / 12$ & 5 \\
\hline
\end{tabular}


Considerando que a presença da complicação poderia interferir no resultado da AV ao longo do tempo, computamos as complicações durante os cinco exames de PVE, das 45 crianças derivadas (91 exames), realizados ao longo do estudo, 68 (67,3\%) exames de PVE foram acompanhados de alguma complicação. As tabelas 7 e 8 representam os dados descritos acima.

Tabela 7: Evolução da variável complicação ao longo do exame

\begin{tabular}{cccccc}
\hline Variável & $\begin{array}{c}\mathbf{n} \\
\mathbf{1}^{\circ} \text { exame }\end{array}$ & $\begin{array}{c}\mathbf{n} \\
\mathbf{2}^{\circ} \text { exame }\end{array}$ & $\begin{array}{c}\mathbf{n} \\
\mathbf{3}^{\circ} \text { exame }\end{array}$ & $\begin{array}{c}\mathbf{4} \\
\mathbf{4}^{\circ} \text { exame }\end{array}$ & $\begin{array}{c}\mathbf{n} \\
\mathbf{5}^{\circ} \text { exame }\end{array}$ \\
\hline \hline c/complicação & 37 & 7 & 10 & 7 & 2 \\
s/complicação & 8 & 11 & 3 & 3 & 3 \\
não realizaram & $\#$ & 27 & 32 & 35 & 40 \\
crianças s/ DVP & 10 & 0 & 0 & 0 & 0 \\
Total & $\mathbf{5 5}$ & $\mathbf{4 5}$ & $\mathbf{4 5}$ & $\mathbf{4 5}$ & $\mathbf{4 5}$ \\
\hline
\end{tabular}

onde: $\mathrm{n}$ = número de crianças; crianças s/DVP = crianças sem Derivação ventrículo-peritoneal. 
Tabela 8: Complicações presentes nos cinco exames de PVE das 45 crianças derivadas.

\begin{tabular}{|c|c|c|c|c|c|}
\hline $\mathbf{N}$ & $1^{\circ}$ exame & $2^{\circ}$ exame & $3^{\circ}$ exame & $4^{\circ}$ exame & $5^{\circ}$ exame \\
\hline $\begin{array}{c}\text { ident. } \\
1 \\
2 \\
3 \\
4 \\
5 \\
6 \\
7 \\
8 \\
9 \\
10 \\
11 \\
12 \\
13 \\
14 \\
15 \\
16 \\
17 \\
18 \\
19 \\
20 \\
21 \\
22 \\
23 \\
24 \\
25 \\
26 \\
27 \\
28 \\
29 \\
30 \\
31 \\
32 \\
33 \\
34 \\
35 \\
36 \\
37 \\
38 \\
39 \\
40 \\
41 \\
42 \\
43 \\
44 \\
45 \\
46 \\
47 \\
48 \\
49 \\
50 \\
51 \\
52 \\
53 \\
55 \\
\end{array}$ & 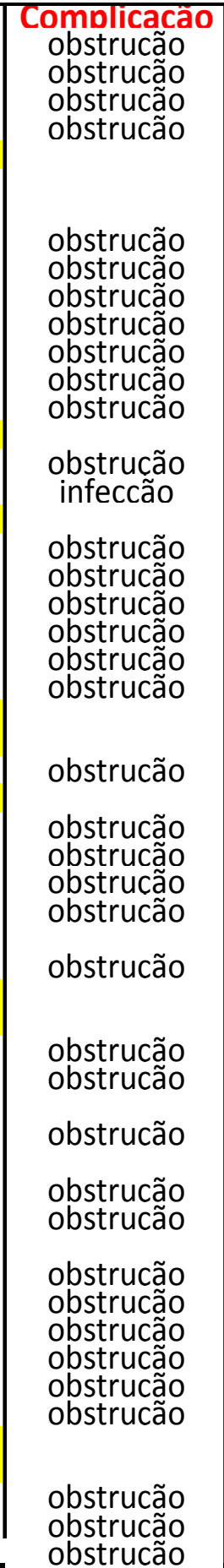 & 更 & $\begin{array}{l}\text { obstrucão } \\
\text { obstrucão } \\
\text { obstrucão } \\
\text { obstrucão }\end{array}$ & $\begin{array}{l}\text { obstrucão } \\
\text { obstrucão } \\
\text { obstrucão }\end{array}$ & obstrucão \\
\hline
\end{tabular}

Onde: ident. = $\mathrm{n}^{\circ}$ de identificação; tarja amarela representa as crianças não derivadas, complicações = obstrução e infecção. 
Como um número considerável de crianças, da nossa amostra, apresentou algum tipo de complicação da hidrocefalia, decidimos comparar a AV das crianças com complicação com a AV das crianças sem complicações, somente ao $1^{\circ}$ exame de PVE.

Neste período foram realizados 55 exames de PVE, sendo 37 exames acompanhados de complicações e 18 exames sem complicações.

A Figura 12 apresenta através de um gráfico de Box- Plot, os resultados da AV das 18 crianças sem complicações com as 37 crianças com complicação. A figura demonstra que a AV do grupo sem complicação foi melhor estatisticamente ao grupo com complicação ( $p=$ 0.0001), representados no gráfico pelo Box-Plot o e 1, respectivamente. 


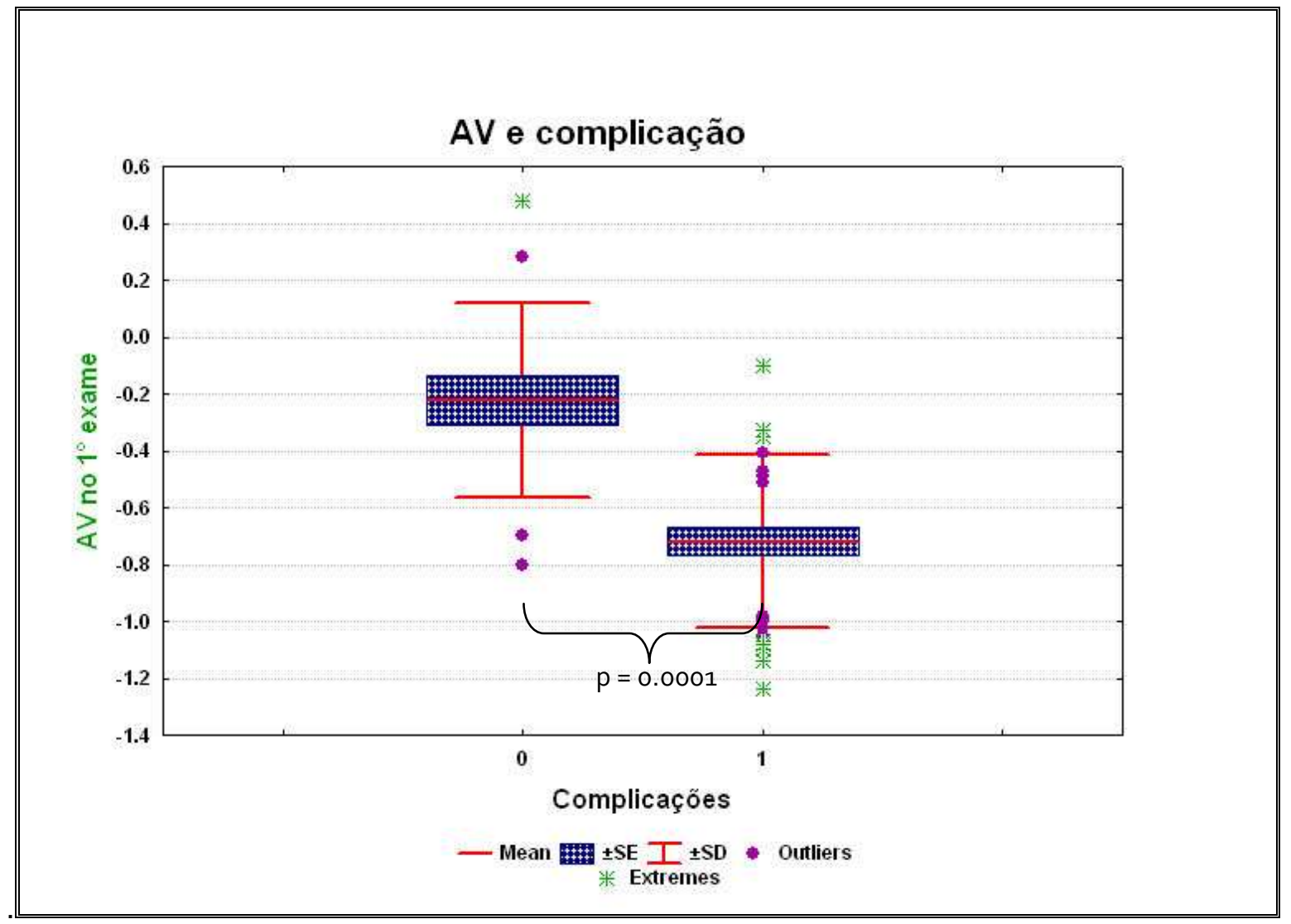

Figura 12: Comparação da AV durante $01^{\circ}$ exame entre os grupos sem complicação, Box-Plot $0=18$ crianças com o grupo com complicação, Box-Plot $1=37$ crianças, O resultado da AV no grupo o é melhor estatisticamente ao grupo 1 ( $p$ o.0001). Análise de variância (Teste de Tukey).

Com a evolução do estudo percebemos que, das 37 crianças que tiveram algum tipo de complicação, como obstrução ou infecção, durante o $1^{\circ}$ exame, somente cinco crianças $(13,5 \%)$, do total de 37 , tiveram resultados positivos quanto ao seu tratamento clínico e não tiveram, durante $02^{\circ}$ exame, as complicações presentes ao $1^{\circ}$ exame.

A figura 13 apresenta através de um gráfico de scatterplot a progressão do resultado da AV das cinco crianças que tiveram alguma complicação da válvula de DVP no $1^{\circ}$ exame e não tiveram no $2^{\circ}$ exame.

Podemos observar que o resultado da $A V$, representado pela linha contínua vermelha é menor no $1^{\circ}$ exame (abcissa) e maior no $2^{\circ}$ exame (ordenada) nas cinco crianças avaliadas (ponto azul). A média em dias entre os dois exames foi de 66.8 dias ( \pm 39.29 dias). 


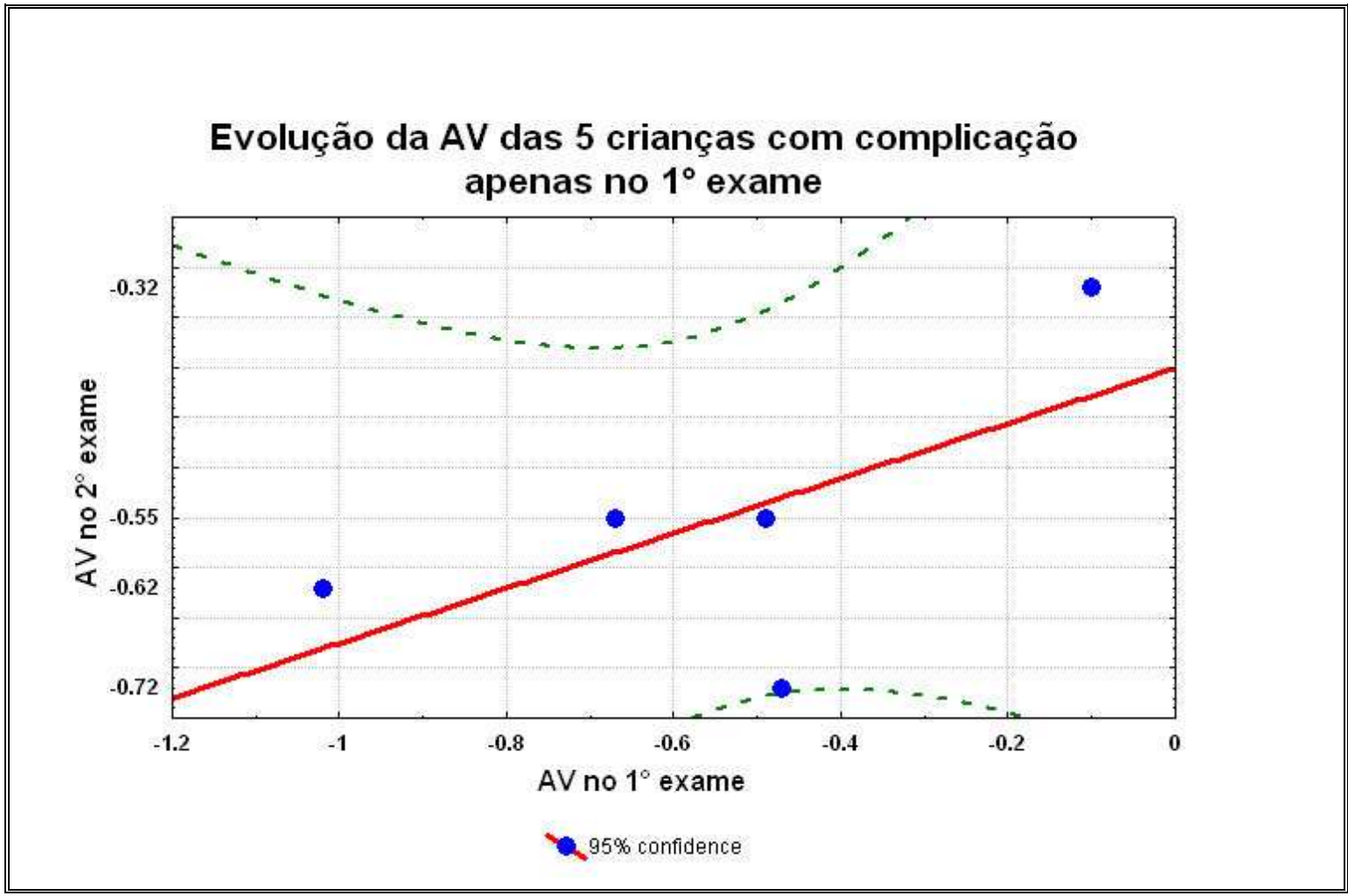

Figura13: onde: abcissa representa a $\mathrm{AV}$ no $1^{\circ}$ exame e a ordenada representa a $\mathrm{AV}$ no $2^{\circ}$ exame. Cada ponto azul demonstrado no gráfico representa uma criança avaliada, a linha continua vermelha representa a média dos exames entre as cinco crianças e a linha pontilhada = desvio padrão. Nota-se melhora da AV entre os dois exames. ( $p$ o.025). Teste de Tukey 
As complicações evoluíram de forma distinta entre os dois primeiros exames. Quando comparamos o resultado da AV das cinco crianças que não apresentaram melhora clínica referente á complicação da DVP entre os dois exames, $1^{\circ}$ e $2^{\circ}$ exames, a média da AV manteve-se igual entre o período dos dois exames.

A figura 14 apresenta através de um gráfico de scatterplot, a média da AV (linha vermelha contínua) no $1^{\circ}$ exame e $2^{\circ}$ exame, das cinco crianças (ponto azul) que não apresentaram melhora clínica entre os dois exames.

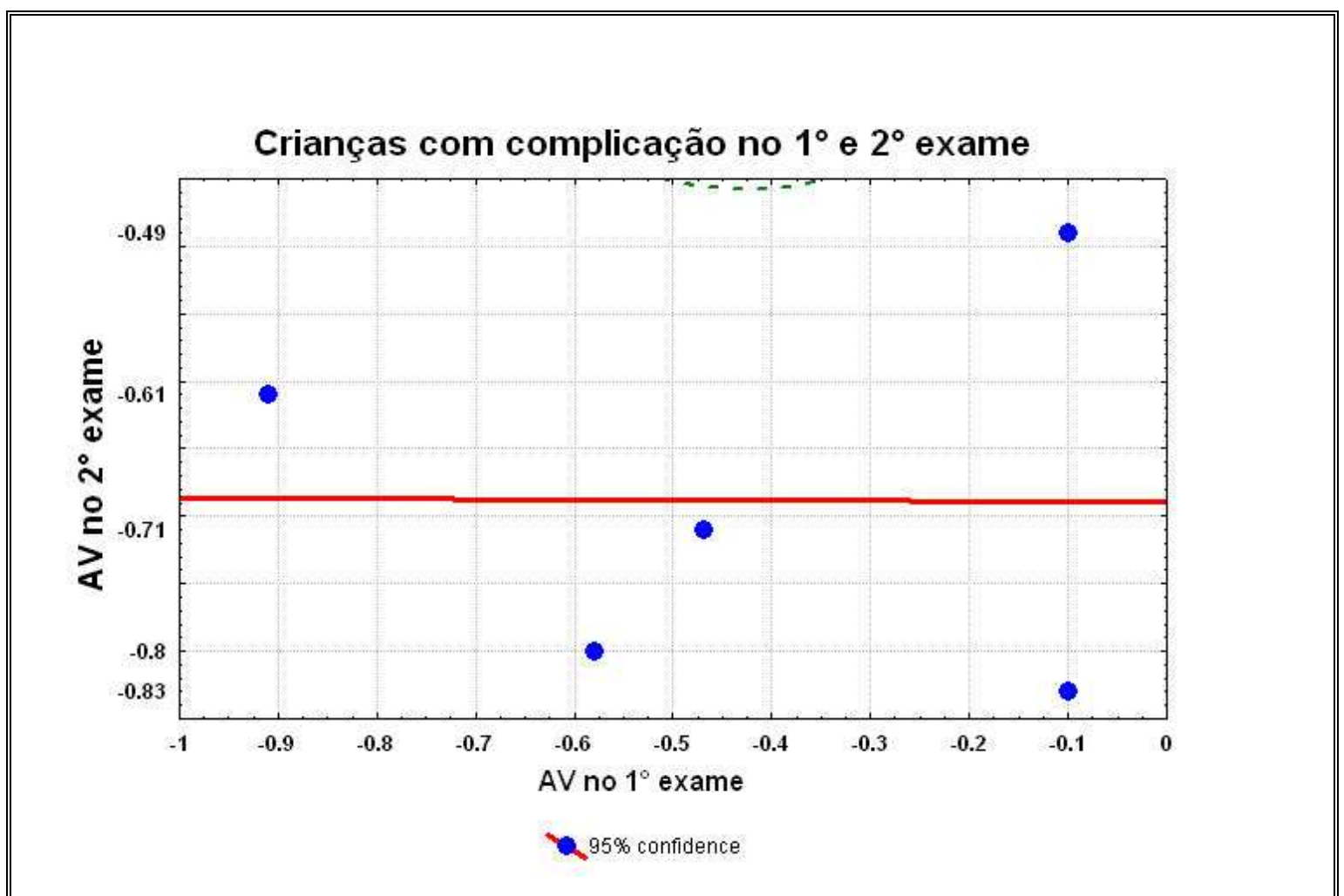

Figura 14: Média da AV entre os dois primeiros exames das 5 crianças que apresetaram complicações no $1^{\circ}$ e $2^{\circ}$ exame, onde: eixo $x$ representa a $A V$ no $1^{\circ}$ exame e o eixo y representa a AV no $2^{\circ}$ exame. Cada ponto azul demonstrado no gráfico representa uma criança avaliada e a linha continua vermelha representa a média da AV das cinco crianças. Nota-se que a AV manteve-se igual entre os exames. ( $p$ o.06o). Teste de Tukey 


\subsubsection{COMPLICAÇÕES NO $2^{\circ} \mathrm{E} 3^{\circ}$ EXAME}

A análise dos resultados da AV evolutiva, comparando as crianças de acordo com o momento de instalação de uma complicação e o momento do teste visual, demonstrou que quanto mais precoce a complicação se instalava, piores eram os resultados dos testes de AV. Ou seja, naquelas crianças em que se observou alguma complicação já na primeira ou segunda avaliação visual, percebemos um maior comprometimento da função visual do que naquelas em que a complicação só foi definida na terceira avaliação e assim por diante, comparando as avaliações subsequentes. Dentre as 13 crianças que realizaram o $3^{\circ}$ exame, sete crianças tiveram alguma complicação já na segunda avaliação, duas crianças a complicação se instalou somente em uma avaliação e quatro não tiveram nenhuma complicação nos dois momentos. As figuras 15 e 16 apresentam gráficos em scatterplot das crianças avaliadas entre os $2^{\circ}$ e $3^{\circ}$ exames e representa os dados descritos acima. A linha continua representa a média entre as medidas de $\mathrm{AV}$ e os pontos azuis representam as crianças avaliadas.

A figura 15 apresenta a média da AV das cinco crianças que tiveram alguma complicação já no segundo momento da avaliação visual. Podemos observar que há uma piora da AV destas crianças. 


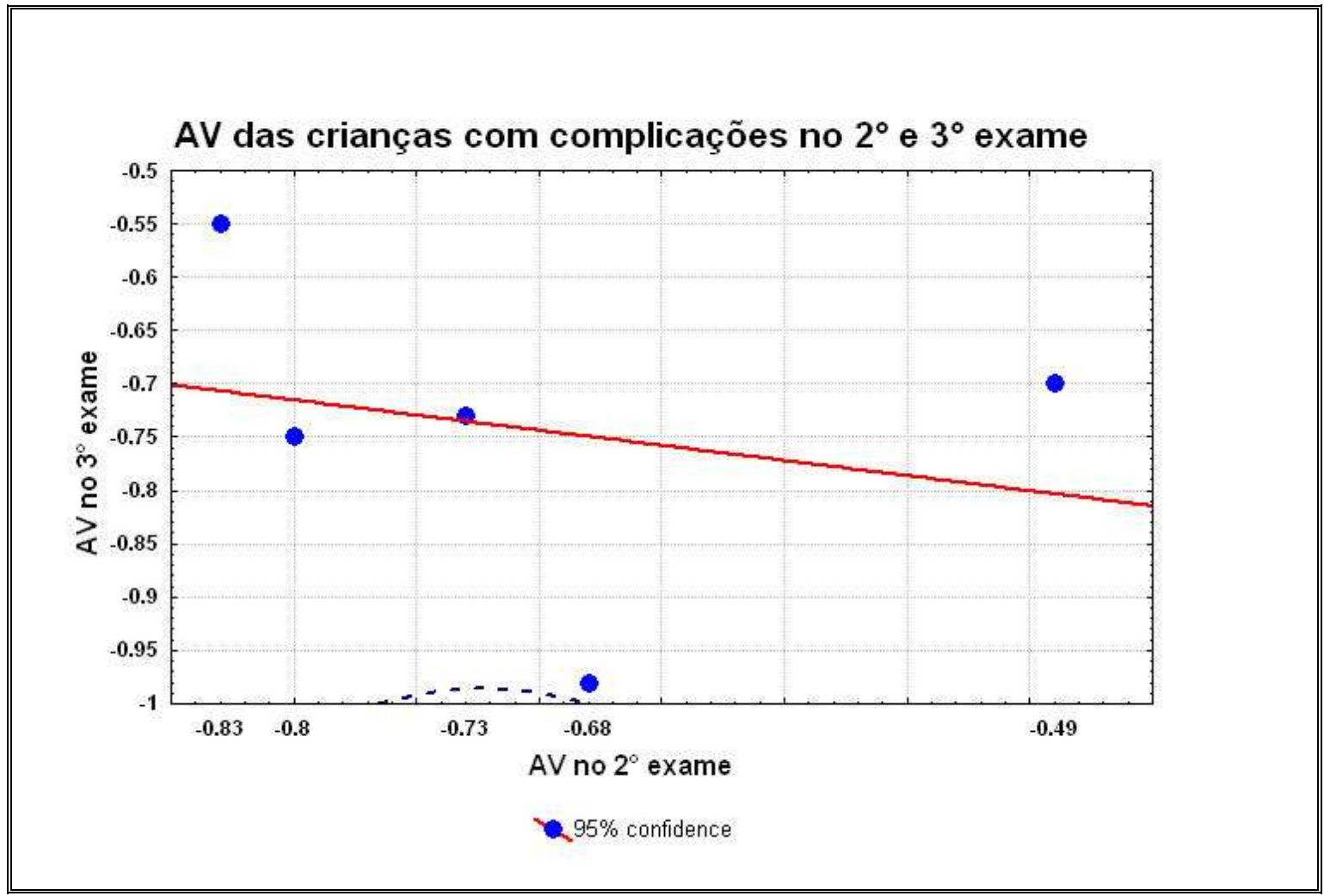

Figura 15: Média da AV das sete crianças que apresetaram complicações no $2^{\circ}$ e $3^{\circ}$ exames, onde: eixo $\times$ representa a AV no $2^{\circ}$ exame e o eixo y representa a $A \bigvee$ no $3^{\circ}$ exame. Cada ponto azul demonstrado no gráfico representa uma criança avaliada e a linha continua vermelha representa a média da AV das cinco crianças. A AV foi pior na $3^{\circ}$ avaliação visual ( $p$ o.001). Teste de Tukey

A figura 16 apresenta a média da AV das duas crianças que tiveram a complicação instalada somente no $2^{\circ}$ momento da avaliação visual. Podemos observar que há uma melhora da AV destas duas crianças. 


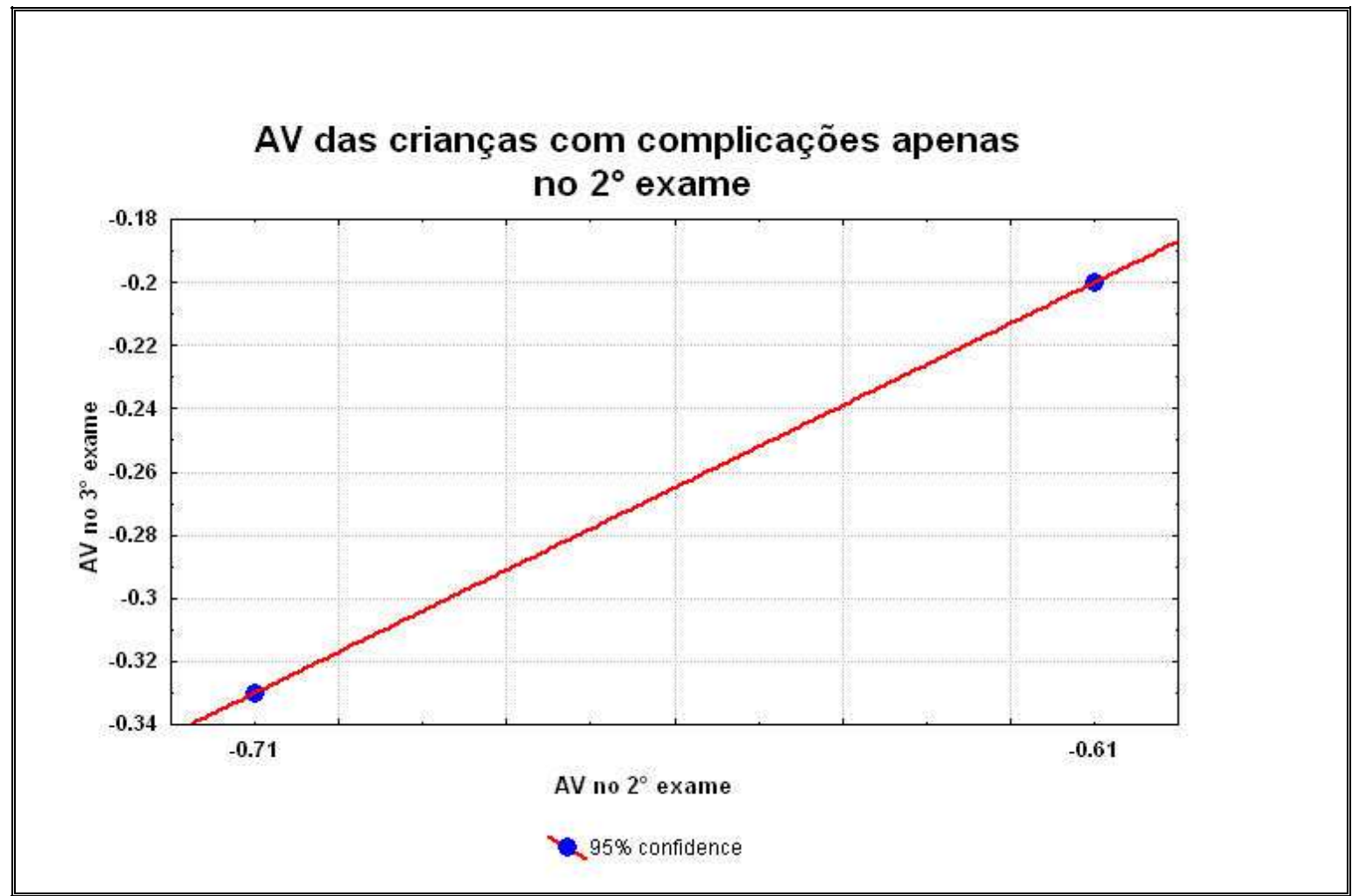

Figura 16: Média da AV das duas crianças que apresetaram complicações somente em um momento da avaliação visual, onde: eixo x representa a $A V$ no $2^{\circ}$ exame e o eixo y representa a $A V$ no $3^{\circ}$ exame. Cada ponto azul demonstrado no gráfico representa uma criança avaliada e a linha continua vermelha representa a média da AV das cinco crianças. A AV foi melhor nas duas crianças (p o.002). Teste de Tukey

Não foi possivel realizar as comparações nas outras avaliações seqüenciais devido ao baixo número de exames realizados. 


\subsubsection{COMPLICAÇÕES E TEMPO DE DERIVAÇÃO}

Uma vez que a presença de complicações e o momento da realização da derivação ventrículo-peritoneal foram determinantes de acuidades visuais mais comprometidas, estudamos a correlação destes dois fatores conjuntamente na tentativa de poder determinar qual destes fatores impõe o maior impacto na piora da função visual.

A figura 17 apresenta um gráfico de Box-Plot que correlaciona o tempo de derivação e presença de complicações na DVP durante o primeiro exame.

O Box-Plot zero (o) representa o grupo de 25 crianças com tempo de derivação $\leq 15$ dias e que complicaram durante a primeira avaliação visual e o Box-Plot 1 representa as 12 crianças com tempo de derivação > 15 dias e que complicaram durante a primeira avaliação.

O grupo de crianças que foi derivado com tempo inferior a 15 dias do diagnóstico da hidrocefalia apresentou resultados de AV estatisticamente superiores às crianças cuja derivação foi realizada com mais de 15 dias $(p=0.029)$. 


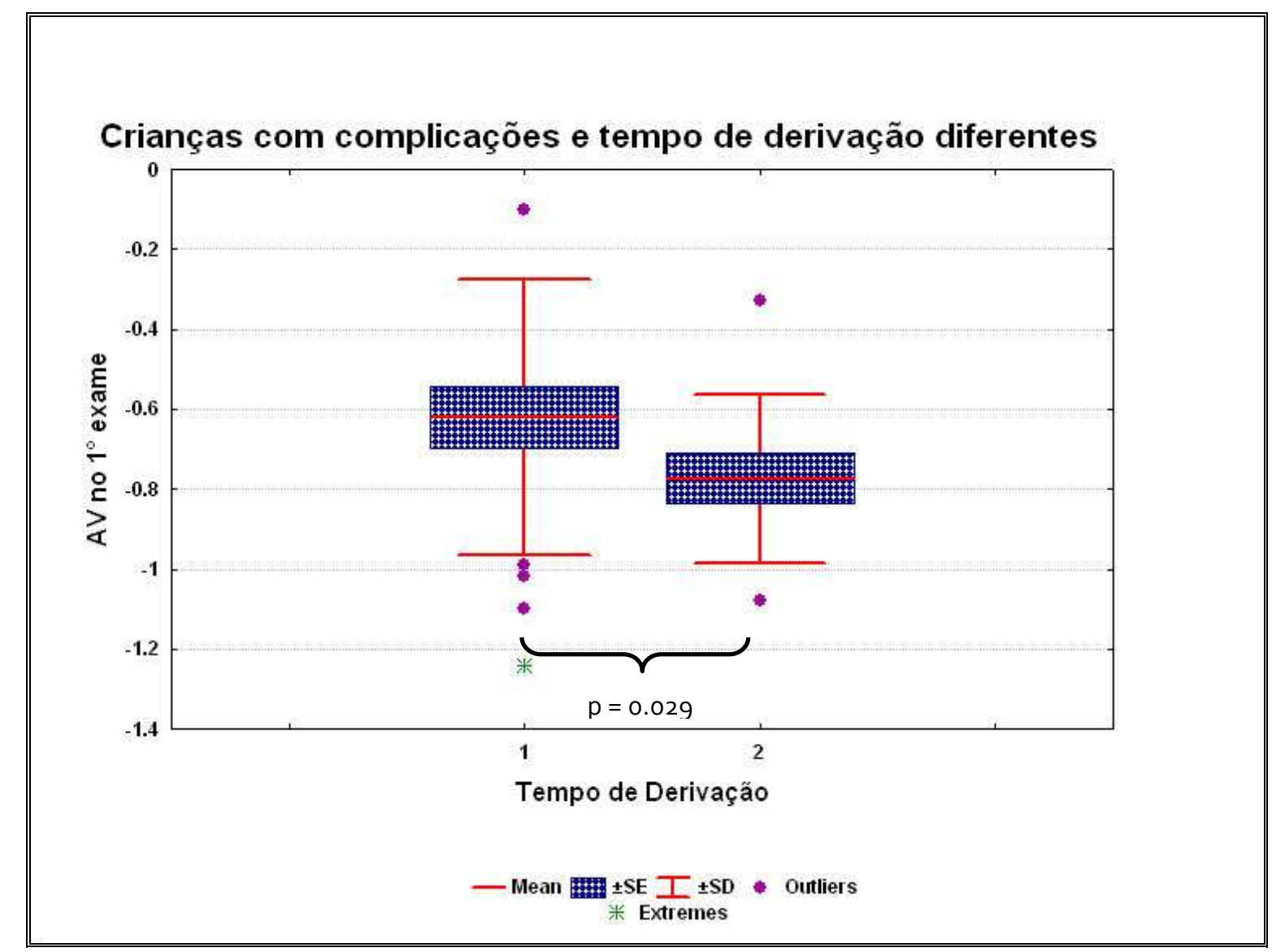

Figura 17: Comparação da AV das 37 crianças que derivaram e complicaram durante $01^{\circ}$ exame. O Box-Plot o representa as 25 crianças que derivaram com tempo $\leq 15$ dias e o Box-Plot 1 representa as 12 crianças que derivaram com tempo > 15 dias, O resultado da AV foi melhor estatisticamente no grupo o (p o.0299). (Teste de Tukey).

Como um número considerável de crianças não derivou (total de 10 crianças) e realizaram somente a primeira avaliação visual resolvemos registrar o valor da AV destas crianças em relação à idade.

A figura 18 apresenta uma análise de regressão linear da AV das 10 crianças sem derivação em diferentes idades. Os dados da figura 18 demonstram que a AV das crianças que não derivaram apresentam uma evolução negativa ao longo do tempo. 


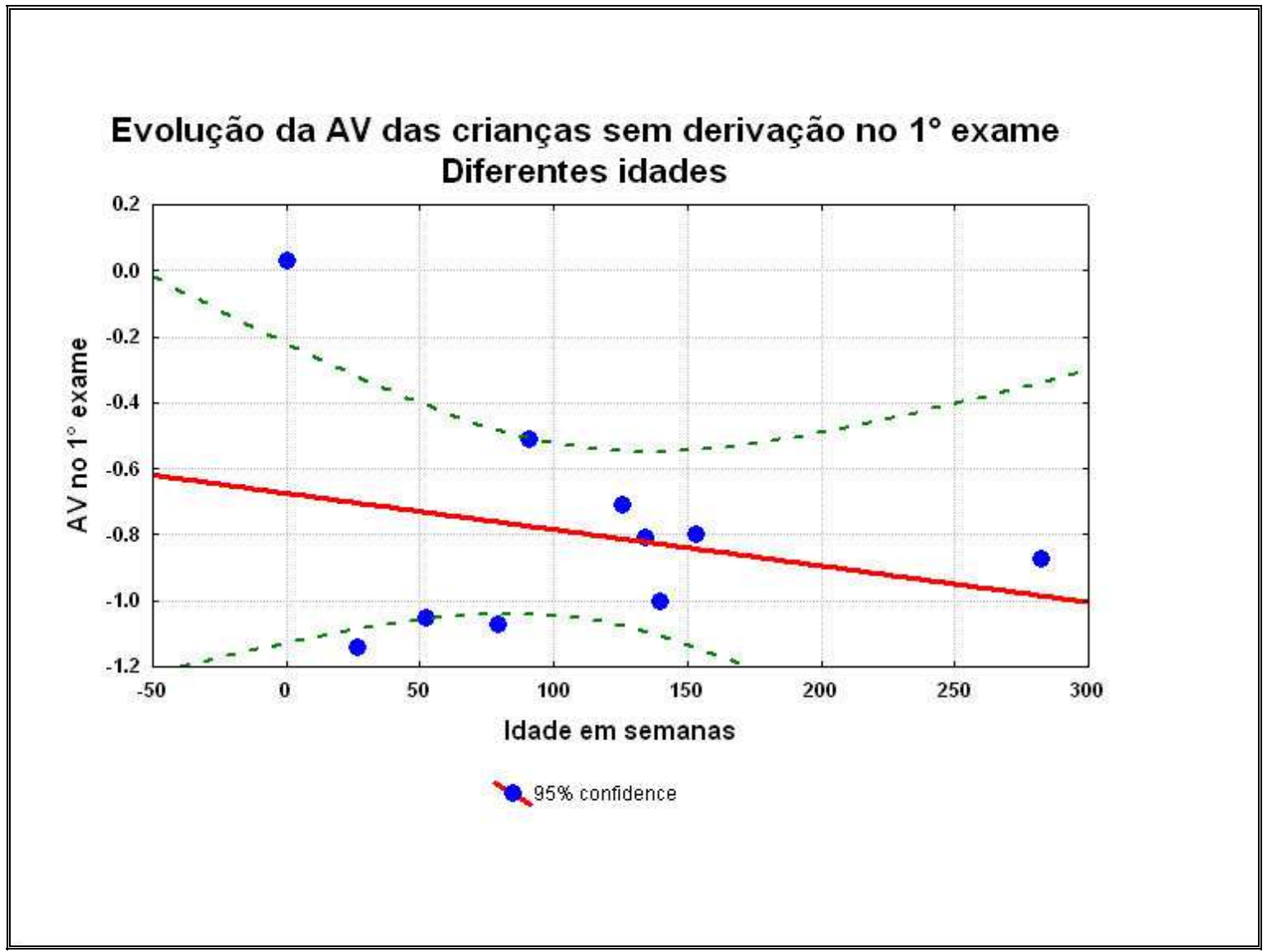

Figura 18: Média da AV das 10 crianças que não derivaram (linha continua vermelha), cada ponto azul no gráfico representa uma criança. Teste de Tukey

As figuras 19 e 20 apresentam os dados referentes às análises das variáveis etiologia e idade gestacional no resultado de AV. É possível verificar pelos dados apresentados que não houve diferença estatística nestas duas variáveis. 


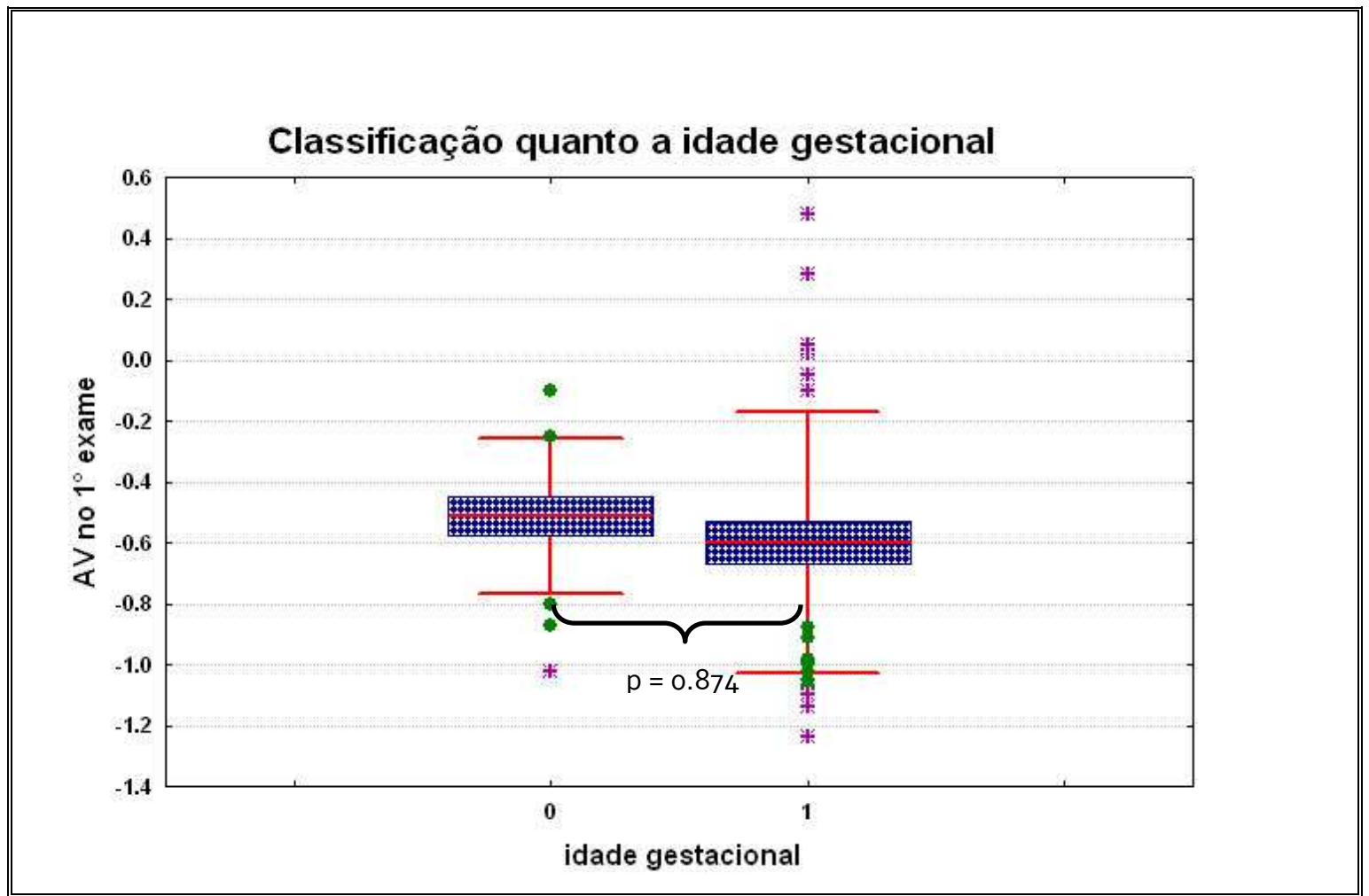

Figura 19: Classificação da idade gestacional e resultado de AV no $1^{\circ}$ exame, onde: Box-Plot o = crianças com idade gestacional > 37 semanas e Box-Plot $1=$ crianças com idade gestacional < 37 semanas. Não há diferença estatística entre as amostras. $(p=0.874)$. 


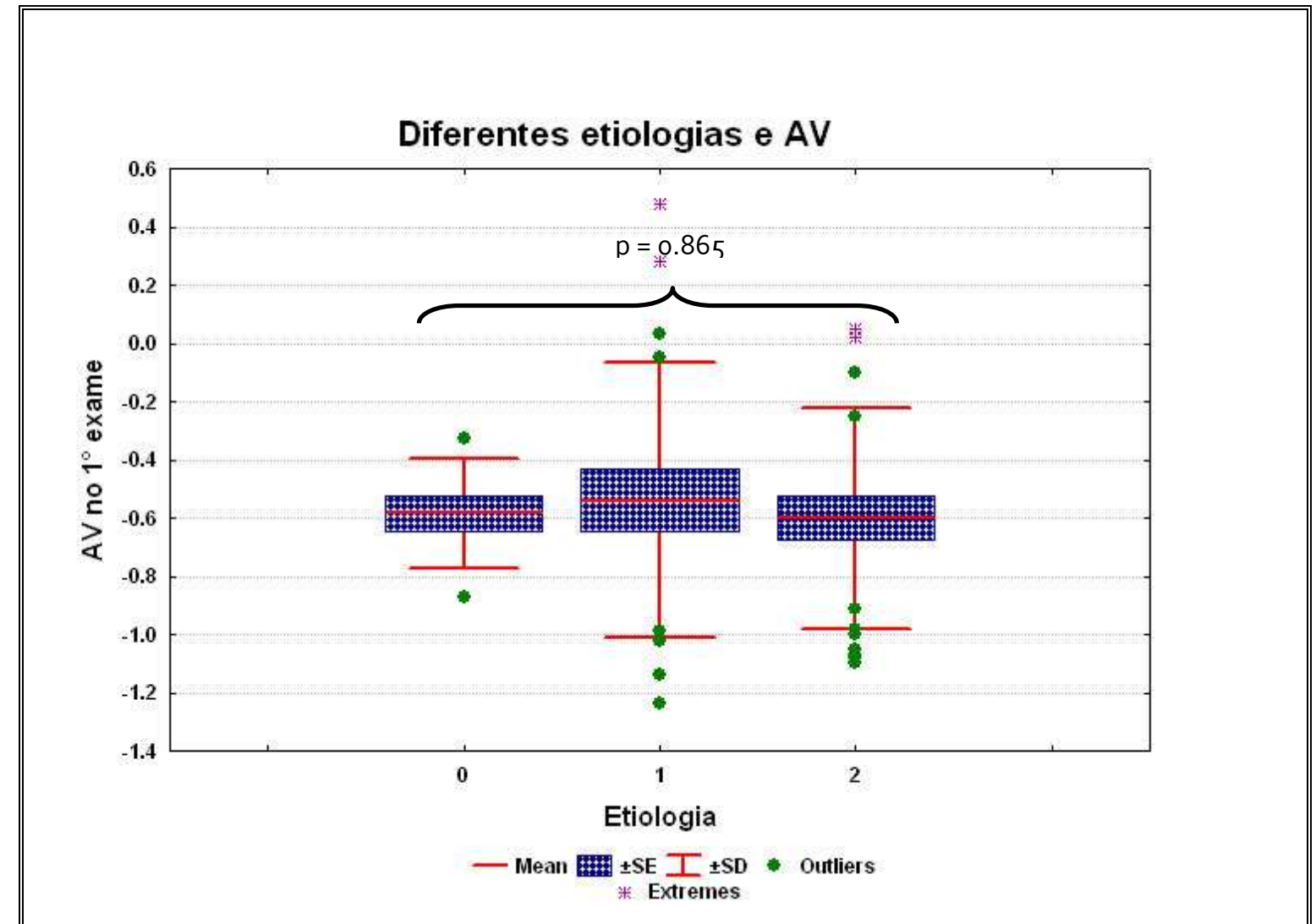

Figura 20: Diferentes etiologias e resultado de $\mathrm{AV}$ no $1^{\circ}$ exame, onde: Box-Plot $0=$ mielomeningocele; Box-Plot $1=$ Hemorragia intraventricular e Box-Plot 2: hidrocefalia isolada. Não há diferença estatística entre as amostras. $(p=$ $0.874)$ 
5.0 DISCUSSÃO

5.0 DISCUSSÃO 
A acuidade visual normal depende da integridade do sistema nervoso central. $\mathrm{O}$ aumento da pressão craniana decorrente da hidrocefalia é um dos fatores, que mais freqüentemente, afeta negativamente a acuidade visual. Um dos primeiros trabalhos a descrever o distúrbio visual como conseqüência da hidrocefalia foi publicado em 1768 por Robert Whytt. Neste trabalho os autores encontraram uma incidência de estrabismo entre 60 a $75 \%$ das crianças com hidrocefalia por eles estudadas (apud Caines et al 2007).

A avaliação da acuidade visual em crianças com hidrocefalia ainda é pouco estudada na literatura. Os trabalhos que envolvem crianças com diagnóstico de hidrocefalia, em sua maioria, incluem casuística retrospectiva e diferentes etiologias. (Heinsenbergen et al, 2002; Paysse, 2002; Reinprecht et al, 2001). Nosso estudo, até onde sabemos, é o primeiro estudo prospectivo, a medir a acuidade visual considerando as diferentes etiologias e complicações.

Importante notar que já no primeiro exame, as crianças com hidrocefalia apresentam valores de acuidade visual reduzidos para a idade, independente de esta avaliação ter sido feita em bebês de até cinco semanas ou em bebês com mais de 12 semanas, correlacionamos este dado com a presença ou não da complicação.

Dentre as cinqüenta e cinco crianças estudadas quarenta e cinco foram derivadas. Considerando as complicações decorrentes da presença da DVP, percebemos que uma grande parte das crianças neste grupo, num total de trinta e sete, sofreram algum tipo de complicação. Dentre as complicações observadas, verificamos que trinta e seis foram por obstrução e uma por infecção que ocorreram ao longo do período de estudo. 
Kliemann; Rosemberg, 2005, afirma em seu estudo que a infecção e as disfunções mecânicas do sistema de derivação constituem as principais complicações da DVP. As complicações mecânicas como, obstrução do cateter de drenagem, têm sido relatadas com freqüência entre $30 \%$ e 60\%, ocorrendo mais freqüentemente nos primeiros dois anos pósderivação. O índice de infecção do sistema de drenagem varia entre $2 \%$ e 15\%, com grande influência sobre a morbidade e qualidade de vida dos pacientes e com risco de mortalidade entre $30 \%$ e $40 \%$.

Considerando que a presença da complicação poderia interferir no resultado da AV ao longo do tempo, computamos as complicações durante os cinco exames de PVE, dos 91 exames realizados com as 45 crianças derivadas, 68 exames de PVE foram realizados em crianças com alguma complicação. Um interessante achado em nosso estudo foi o fato do grupo que evoluiu sem complicações apresentar melhor valor de acuidade visual comparado ao grupo com complicações.

Outro importante fator relacionado às complicações e seu impacto no sistema visual é o fato de que quanto mais complicações tolerava a criança, maior era a redução no desenvolvimento da acuidade visual com o passar da idade, uma vez que os valores de acuidade visual permaneceram semelhantes e o que se esperava era que houvesse uma evolução desta função, normalmente observada nesta idade em crianças normais. As crianças que apresentaram complicações em dois exames consecutivos obtiveram valores de acuidade visual menores àquelas crianças que apresentaram complicações em apenas um exame. Mais uma vez, não encontramos na literatura trabalhos que correlacionasse o número de complicações da DVP com a função visual ao longo do tempo. 
Outro resultado inédito que obtivemos mostra que o tempo entre o diagnóstico e a intervenção cirúrgica para a realização da derivação interfere negativamente na qualidade desta função visual. Isso porque as crianças que tiveram uma latência maior que 15 dias entre o diagnóstico de necessidade de derivação e a realização do procedimento, apresentaram piores valores de acuidade visual.

Este achado é de grande impacto e apresenta mais uma informação a considerar que pode auxiliar a equipe médica no momento de decidir quanto aos procedimentos, principalmente o cirúrgico, a serem realizados.

Inúmeros estudos retrospectivos acompanham a evolução das crianças com diagnóstico de hidrocefalia tratadas cirurgicamente em relação ao tempo de instalação da válvula, porém, nestes, o desenvolvimento neurológico e cognitivo são os únicos focos das investigações (Vinck et al, 2006; Gabrielli et al, 2004; Heinsenbergen et al, 2002; Ladewig, 2000; Fobe et al, 1999; Hirsch et al, 1998). Vários fatores de risco têm sido relatados, como etiologia da hidrocefalia associado à patologia, complicações da derivação como infecção e número de revisões e pelo que sabemos, nenhum estudo mediu a acuidade visual prospectivamente nesta população. Em nosso estudo, os procedimentos de derivação e complicações ocorreram durante as realizações das medidas de acuidade visual, o que nos permitiu estudar sua evolução e o impacto destes fatores nesta função visual.

Dos poucos trabalhos que avaliam a acuidade visual podemos citar o de Biglan em 1995 que avaliou retrospectivamente 298 crianças com idade entre um e 31 anos e diagnóstico de Mielo. Neste trabalho os parâmetros analisados foram: acuidade visual função binocular e presença estrabismo. Os autores descrevem uma incidência de $94 \%$ para crianças com diagnóstico de hidrocefalia e DVP. A acuidade visual média, em $85 \%$ desta 
amostra, foi de $20 / 40$ (Teste de Snellen) e 61\% destas crianças tiveram o estrabismo em algum momento do estudo. Esta forma de se apresentar os valores de acuidade visual, presente em muitos artigos merece uma crítica. Os valores de acuidade visual se modificam com a idade e uma acuidade de 20/20 na tabela de Snellen, considerada normal, só é obtida de 5-7 anos de idade. Desta forma, crianças com acuidade de 20/40 podem ter acuidade normal para a idade. Outro ponto é que complicações entre outros fatores não são considerados, o que põe em questão este tipo de conclusão.

O tempo de derivação como um complicador para crianças com diagnóstico de hidrocefalia tratadas cirurgicamente foi descrito no trabalho de Heinsenbergen, 2002. Os autores com o objetivo de encontrar o principal fator de risco para as crianças com hidrocefalia correlacionam o tempo de derivação com os resultados de um questionário utilizado pela Organização Mundial de Saúde (WHO) para a classificação internacional de injúrias e desabilidades que avalia: injúrias de audição, visão, musculoesqueléticas, fala e linguagem e epilepsia. Este estudo avaliou retrospectivamente 137 crianças e os autores concluíram que o tempo de implantação da válvula de derivação é o que define o prognóstico das crianças com hidrocefalia tratadas cirurgicamente. As crianças que foram derivadas no tempo maior que 30 dias obtiveram pior resposta em todos os quesitos do questionário WHO, exceto audição. Como o foco do seu trabalho não foi avaliar a acuidade visual e os dados foram coletados retrospectivamente, os autores não deixam claro quais foram às alterações encontradas em cada um dos quesitos avaliados pelo questionário.

O impacto do tempo de derivação sobre funções cognitivas já havia sido estudado por Fobe 1999, mostrando que há prejuízos cognitivos em crianças com derivação posterior a sete dias do diagnóstico de necessidade de derivação. Nossos resultados concordam com 
estes estudos, uma vez que mostra uma redução na acuidade visual de crianças que foram derivadas com mais de 15 dias de verificada a necessidade de implantação da DVP, quando comparados com o grupo de crianças que derivou com até 15 dias. Nossos dados associados aos achados de Fobe et al, (1999) e Heinsenbergen et al, (2002) sugerem que o período entre derivação e o diagnóstico de sua necessidade é fundamental para reduzir prejuízos das funções corticais, indicando que quanto menor este período, melhor são estas funções.

A acuidade visual das crianças que não foram derivadas também apresentou valores abaixo do esperado. Num total de 10 crianças em nosso estudo, não realizaram tratamento cirúrgico para controle da hidrocefalia. Acreditamos que a DVP não foi indicada porque em algumas situações ocorre a compensação da hidrocefalia. As estruturas ósseas dos bebês são maleáveis, podendo se expandir e conseqüentemente controlar o aumento da pressão intracraniana e compensar a hidrocefalia, porém esta maleabilidade é limitada e com o tempo o que estava compensado se torna lesivo, comprime vias visuais e provoca dano ao desenvolvimento da função visual. Entretanto, este mecanismo compensatório não foi eficiente em nossa amostra. Quando comparamos os valores da acuidade visual deste grupo aos valores de acuidade visual do grupo que derivou com tempo menor que 15 dias, observamos pior resultado no grupo sem derivação. Isso pode ser divido a vários fatores, mas, podemos pensar que a compensação realizada pela expansão dos ossos cranianos não seja suficiente para a redução total da pressão. Desta forma, os danos causados pela pressão levemente aumentada, mas que persiste por muitos anos, afetaria de maneira contínua as estruturas do sistema visual e levaria à baixa de acuidade visual que verificamos em nossas crianças. 
Por outro lado, Caines (2007) avaliou evolutivamente por três anos, 20 crianças com diagnóstico de Mielo associado à hidrocefalia. A proposta do estudo foi descrever os achados neuro-oftalmológicos nos quatro primeiros anos entre o grupo com derivação e o grupo sem derivação. Os resultados revelaram poucas anormalidades entre os dois grupos e nenhuma das crianças sem derivação apresentou algum defeito óculo-motor. A análise dos dados deste autor fica prejudicada uma vez que o autor não descreve o número de revisões realizadas nas crianças que necessitaram de derivação e também não descreve o tempo entre o diagnóstico e a primeira derivação. Outra consideração importante a ser feita é que este estudo não contradiz os nossos resultados que mostram diferenças entre os grupos derivados e não derivados. As alterações oftalmológicas verificadas clinicamente no exame neuroftalmológico são pouco precisas. Vários estudos realizados em nosso laboratório mostram alterações de funções visuais em pacientes que apresentam avaliação oftalmológica considerada normal (Ventura et al., 2007, Costa et al., 2007, Moura et al., 2008). Mesmo as alterações de motilidade ocular necessitam de um aumento considerável de pressão intracraniana para ocorrer.

Uma vez que a presença de complicações e o momento da realização da DVP foram determinantes de acuidades visuais mais comprometidas, estudamos a correlação destes dois fatores conjuntamente na tentativa de poder determinar qual destes fatores impõe o maior impacto na piora da função visual. A figura 18 apresentou a correlação do tempo de derivação e presença de complicações na DVP durante o primeiro exame. Nossos dados revelam que o grupo de crianças que foi derivado com tempo inferior a 15 dias do diagnóstico da hidrocefalia apresentou resultados de acuidade visual estatisticamente 
superior às crianças cuja derivação foi realizada com mais de 15 dias. Não encontramos na literatura dados que confrontem nossos resultados.

As análises comparativas considerando os fatores como a etiologia, o peso ao nascimento e a idade gestacional não demonstraram correlação com o valor de acuidade visual.

A base da saúde visual deve ser estruturada e fortalecida nos primeiros anos de vida, enquanto é possível reverter e tratar as alterações. Deparamo-nos com uma contradição: grande avanço tecnológico que beneficia o controle e o diagnóstico da hidrocefalia, mas pouca atenção à prevenção, à garantia do desenvolvimento visual normal nos casos de crianças com grandes números de revisões e tempo de derivação estendido.

A visão é um dos mais importantes sentidos no desenvolvimento físico e cognitivo normal da criança. A criança necessita ver para desenvolver a sua visão, e até que a AV esteja totalmente estabelecida, qualquer obstáculo à formação de imagem, pode levar a um mau desenvolvimento visual, que se tornará irreversível se não tratado em tempo hábil (Arippol; Salomão; Belfort, 2006).

Distintos aos dados descritos pela literatura (Spencer 2006, Graziano; Leone, 2002, Guerra et al, 1995) nossos resultados mostram que o valor da acuidade visual não foi diferente entre os três grupos estudados, mielomeningocele, hemorragia intraventricular e hidrocefalia isolada. Os três grupos apresentaram valores de acuidade visual inferior à normalidade, mas não há diferença estatística entre eles. Em nossos dados, as etiologias congênitas e adquiridas tiveram a mesma incidência. 
Shokunbi (2002), com o objetivo de comparar a função visual de crianças com diagnóstico de hidrocefalia a diferentes etiologias encontra resultados similares ao nosso e conclui que a dilatação ventricular é fator determinante de danos visuais independente do diagnóstico de origem da hidrocefalia; quanto maior a dilatação ventricular, maior o risco de comprometimento da função visual. Os autores avaliaram 20 crianças com diagnóstico de hidrocefalia e diferentes etiologias e idade média abaixo de 18 meses.

Em suma, os estudos existentes referentes ao acompanhamento a longo prazo dos pacientes com hidrocefalia são exclusivamente retrospectivos, dificultando tanto a comparação entre eles em razão de diferentes metodologias para obtenção de dados e de avaliação da função visual, quanto à análise do impacto a longo prazo do tratamento da hidrocefalia no prognóstico dos pacientes. A inclusão de diversas etiologias para a hidrocefalia nos diferentes estudos sem a sua devida análise como um fator importante para o entendimento do quadro visual funcional da doença e a multiplicidade de influências sobre a amostra estudada também representam um obstáculo aos estudos comparativos.

Nosso trabalho foi o primeiro a avaliar prospectivamente, a acuidade visual de crianças com diagnóstico de hidrocefalia tratadas cirurgicamente nos primeiros anos de vida, e correlacionar o resultado com o tempo de derivação e número de complicações.

Apesar da grande evolução tecnológica alcançada pela oftalmologia, ainda não somos capazes de prevenir as alterações visuais detectáveis pelo simples exame da acuidade visual nas crianças com hidrocefalia. A indicação da válvula de derivação e o tratamento para as complicações ainda são medidas retardadas devido à prematuridade, instabilidade hemodinâmica e a não autorização do familiar. Estes motivos podem comprometer o desenvolvimento visual destas crianças e conseqüentemente, alterar seu 
desenvolvimento motor e a sua capacidade de comunicação porque gestos e condutas sociais são apreendidos pela resposta visual.

A instalação precoce da válvula de derivação, o tratamento efetivo para minimizar o número de complicações e um programa de estimulação visual precoce, permite que a criança possa ter uma integração maior com seu meio. 
6.0 CONCLUSÃO 


\section{6.o CONCLUSÃO}

A acuidade visual foi medida com sucesso em crianças com hidrocefalia pelo método dos potenciais visuais evocados de varredura.

O tempo entre diagnóstico de necessidade de derivação e a cirurgia bem como as complicações pós-derivação são fatores críticos a serem considerados para um bom prognóstico visual. 
7.0 ANEXOS 


\section{TERMO DE CONSENTIMENTO E ESCLARECIMENTO (Anexo 2)}

Seu(ua) filho(a) está sendo convidado(a) a participar de um estudo que está sendo desenvolvido no Laboratório de Neurobiologia da Visão com a colaboração do Hospital Israelita Albert Einstein pela Fisioterapeuta, Silvana Alves Pereira, Hospital Israelita Albert Einstein, Telefone nº 3747-1518. Se tiver alguma dúvida deste estudo ou seus direitos enquanto participantes, favor entrar em contato com Dr. José Pinus, presidente do Comitê de Ética em Pesquisa 3747-3007. A proposta da pesquisa é obter informações sobre a evolução da acuidade visual em pacientes com diagnóstico de hidrocefalia, nos 12 primeiros meses de vida através dos potenciais visuais evocados de varredura. Este teste consiste no registro de sinais elétricos gerados na região posterior da cabeça (região occiptal) onde se localiza à parte do cérebro que processa as informações visuais. Para a execução deste teste, serão colocados pequenos discos metálicos (eletrodos) sobre o couro cabeludo de seu (ua) filho (a) com creme especial. Durante o exame seu (ua) filho (a) poderá permanecer sentado em seu colo enquanto observa um monitor de TV onde listras brancas e pretas serão apresentadas. Cada olho será testado separadamente a partir dos 6 meses, usando um tampão adesivo antialérgico. No final do teste, uma medida da acuidade visual (visão) de cada olho estará disponível. O beneficio dado por este teste é a medida da visão de cada olho. Não há risco algum neste teste.

Os dados serão sigilosos e o nome dos pacientes não serão divulgados. Caso ocorra detecção de qualquer problema oftalmológico será feito encaminhamento para o tratamento necessário. O exame será fornecido sem nenhum custo para você

Você pode esclarecer suas dúvidas sobre quaisquer aspectos deste estudo bem como desistir a qualquer momento que desejar. A participação no exame é totalmente voluntária. Sua assinatura neste termo de consentimento indica que você concorda na utilização dos resultados deste exame para pesquisa, após ter lido a informação descrita acima (ou alguém ter lido para você).

Nome da Pessoa que conduziu discussão:

Assinatura do Pesquisador: Data e Hora:

Nome do Responsável:

Assinatura do Responsável: Data e Hora:

Inicias do paciente: PVE No.: 
8.0 REFERÊNCIAS BIBLIOGRÁFICAS 


\section{8.o REFERÊNCIAS BIBLIOGRÁFICAS}

Arippol, P. K. K.; Salomão, S. R.; Belfort JR., R. (2006). Método computadorizado para medida da acuidade visual. Arquivos Brasileiros de Oftalmologia, 69 (6), 907-914.

Atkinson, J.; Braddick, O. (1989). Development of basic visual fuctions. In: SLATER, A.; BREMNER, G. (Eds.) Infant Development. Lawrence Erlbaum Associates.

Bicas, H.E.A. (2002). Visual acuity. Measurements and notations. Arquivos Brasileiros de Oftalmologia, 65 (3), 375-384.

Biglan AW. (1995). Strabismus Associated With Meningomyelocele. J. Pediatr. Ophthalmol. Strabismus. 32, 309-314.

Birch, E.E. \& O'Connor, A.R. (1991). Forced-choice preferential looking acuity of children with cortical visual impairment. Development Medicine and child neurology, 33, $772-729$.

Caines, E.; Dahl M.; Holmstro, G. (2007). Longterm oculomotor and visual function in spina bifida cystica: a population-based study. Acta Ophthalmol. Scand.: 85: 662-666.

Cavalcanti D.P.; Salomão M.A. (2003). Incidência de hidrocefalia congenital e o papel do diagnóstico pré-natal. J. Pediatria (RJ): 79 (2), 135-140. 
Cedzich, C.; Schramm, J.; Wenzel, D. (1990). Reversible visual loss after shunt malfunction. Acta Neurochir (Wien), 105, 121-123.

Costa, M. F. Acuidade visual de resolução de grades em crianças com paralisia cerebral do tipo espástico pelo método dos potenciais visuais evocados de varredura. São Paulo, 2001. 69p. Dissertação (Mestrado) - Instituto de Psicologia da Universidade de São Paulo.

Costa M.F, Salomão S.R; Berezovsky A; De Haro F.M \& Ventura DF. (2004). Relationship Between Vision And Motor Impairment In Children With Spastic Cerebral Palsy: New Evidence From Electrophysiology. Behavior Brain Research, 149, 145-150.

Costa, M. F.; Oliveira, A. G. F. ; Feitosa-Santana, C. ; Zatz, M. ; Ventura, D. F. (2007). Red-Green Color Vision Impairment In Duchenne Muscular Dystrophy. American Journal Of Human Genetics, V. 80, 1064-1075.

Cronemberger, M. F.; Tabuse M.K.U.; Aguilar L. T.; Costa M. F.; Ferraretto I. (1999). Achados oculares em pacientes com mielomeningocele: 72 casos. Arq. Bras. Oftalmol. 63(5), 379-382.

Cruz, A.A.V.; Salomão, S.R. (1998). Acuidade visual. Arq. Bras. Psicol., 50, 9-26. 
Courage, M.L. \& Adams, R.J. (1990). Visual acuity assessment from birth to 3 years using the acuity card procedure - cross sectional and longitudinal samples. Optometry and vision science, $67,713-718$.

Davidoff Le (1995): Treatment Of Hydrocephalus. Arch Surg 18: 1737-1762,

Delisa, J. A. (1992). Medicina de Reabilitação: Princípios e Práticas. São Paulo, Manole, 469-473.

Dobson, V.; Mayer, D.L.; Lee, C.P. (1990). Visual acuity screening of preterm infants. Invest. Ophthalmol. Vis.Sci., 19, 1498-1505.

Drake, J. M.; Sainte-Rose C. (1995). The Shunt Book. Cambridge, Ma: Blackwell Science, 3-12.

Fantz, R.L. (1958). Pattern vision in yong infants. Psychol.Rec., 8, 43-47.

Fobe, J. L. Rizzo, A. M. P. P.; Silva, I. M.; Silva, S. P. M.; Teixeira, C. E.; Souza, A. M. C.; Fernandes, A. (1999). Ol em pacientes com hidrocefalia e mielomeningocele: Implicações do tratamento cirúrgico. Arq. Neropsiquiatr. 57(1), 44-50.

Furuskog, P.; Wagner, P. (1986). Visual acuity measurement using evoked potentials and fast fouries transform. Acta Ophthalmol., 64, 325-355. 
Gabrieli A.P.T.; Vankoski, S.; Dias, L.C.; Milani, C.; Lourenço A. (2004). Análise laboratorial de marcha na mielomeningocele de nível lombar baixo e instabilidade unilateral de quadril. Acta Ortop Bras. 12 (2), 91-99.

Gaston, H. (1991). Opthalmic Complications of sipina bífida and Hydrocephalus. Eye 5, 279-290.

Gorman, J.J.; Cogan, D.G.; Gellis, S.S. (1957). An apparatus for grating the visual acuity of infants on the basis of optokinetic nystagmus. Pediatrics, 19, 1088-1092.

Gottlob,I.; Fendick, M.G.; Guo, S.; Zubcov, A.A.; Odom, J.V.; Reinecke, R.D. (1990). Visual acuity measurements by swept spatial frequency visual-evoked-cortical potentials (VECPs): Clinical application in children with various visual disorders. J. Ped. Ophthalmol. Strab., 27,40-47.

Graziano R.M.; Leone C.R. (2002). Problemas oftalmológicos mais freqüentes e desenvolvimento visual do pré-termo extremo. J. Pediatr (Rio J);81 (1 Supl): S95-S100.

Greve, J.A., (2001). Diagnóstico e Tratamento da Lesão Medula Espinhal. $1^{\text {a }}$ ed. São Paulo: Roca.

Guerra A.B.; Diniz E.Ma.A.; Krebs V.L.J.; Ceccon M.E.J.; Ferbaum R.; Vaz F.A.C.; Ramos J.L.A. (1995). Estudo Clínico - Evolutivo de 63 Recém-Nascidos Portadores de Hemorragia Intracraniana. Pediatria, 17 (3), 117-122. 
Harding, G. F. Odom JV; Spileers W \& Sperreijie H. (1996). Standard for visual evoked potencial. Vision Research, 36, 357-3572.

Harmer R.D.; Norcia, A.M.; Tyler C.W.; Hsu-Winges, C. (1989). The development of monocular and binocular VEP acuity. Vis. Res. 29 (4), 394-408.

Harmer R.D.; Mayer, D.L. (1994). The development of spatial vision. In: Albert, D.M.; Jakobiec, F.A. ed. Principles and practice of ophthalmology: basic sciences. Philadelphia. WB Saunders, 578-608.

Harvey, M. E. Dobson V; Luna Bi Scher M.; (1997). Grating acuity and visual-field. Development in children with intraventricular hemorrhage. Development medicine \& child neuology, 305-312.

Heikkinen, A. M.; Mustonen, E (1987). Ophthalmic changes In Hydrocephalus. A Follow-up examination of 50 patients treated with shunts. Acta Ophthalmogia. 65: p. 81-86.

Heisensbergen, I.; Rottevell, J.; Roeleveld, N.; Grottenhuis, A. (2002). Outcome in shunted hydrocephalic children. European Journal of Paediatric Neurology:6, 99-107.

Hirsch, E. H.; Laroussinie, F.; Brunet, L.; Sainte-Rose, C.; Renier, D.; Cinalli, G.; Zerah, M.; Pierre-Kahn, A. (1998). Late outcome of the surgical treatment of hydrocephalus Child's Nerv Syst 14: 97-99. 
Holladay, J.T. (1997). Proper method for calculating average visual acuity. J. Refrac.Sur., 13, 388-390.

Jason I. Lifshutz, M.D. and Walter D. Johnson, M.D. (2001). History of Hydrocephalus And Its Treatments. Neurosurg Focus 11 (2), 1-5.

Katsumi, O.; Arai,M.; Wajima, R.; Denno, S.; Hirose, T. (1996). Spatial frequency sweep pattern reversal VER acuity VS Snellen visual acuity: Effect of optical defocus. Vis. Res., 36, 903-909.

Kliemann S.E.; Rosemberg .S. (2005). Hidrocefalia Derivada na Infância:Um estudo clínico-epidemiológico de 243 observações consecutivas. Arq Neuropsiquiatr; 63 (2), 494501.

Kolb,H., Fernandez,E., Nelson,R., \& Jones.W. Recuperado em og de junho de 2007. Webvision - the Organization of the retina and visual system. University of Utah.

http://webvision.med.utah.edu/kallSpatial.html.

Ladewig, I. (2000). A Importância Da Atenção Na Aprendizagem De Habilidades Motoras. Rev. paul. Educ. Fís., São Paulo, supl.3, 62-71.

Mankinen-Heikkinen, A.; Mustonen, E. (1987). Ophthalmic changes in hydrocephalus: A follow-up examination of 50 patients treated with shunts. Acta Ophthalmologica, $65,81-$ 86. 
Matushita, H.; Almeida, G. G. M. (1992). Hidrocefalia congênita In: Diament, A.; Cypel, S. editores. Neurologia Infantil. São Paulo: Atheneu, 704-723.

Mayer, D.L.; Beiser, A.S.; Warner, A.F.; Pratt, E.M.; Raye, K.N.; Lang, J.M. (1995). Monocular acuity norms for the Teller acuity cards between ages one month and four years. Invest. Ophthalmol. Vis. Sci.; 36, 671-685.

Mccullough, D. C. (1990). History of the treatment of Hydrocephalus, in scott Mr (Ed): Hydrocephalus. Williams \& Wilkins. Baltimore,3, 1-10.

McDonald, M.A.; Dobson, V.; Sebris, S.L.; Baitch, L.; Verner, D.; Teller, D.Y. (1985). The acuity card procedure: A rapid test of infant acuity. Invest. Ophthalmol. Vis.Sci, 26, $1158-1162$.

Moura Ala, Teixeira Raa, Oiwa Nn, Costa Mf, Callegaro D, Hamer Rd, Ventura Df. (2008). Chromatic Discrimination Losses In Multiple Sclerosis Patients With And Without Optic Neuritis Using The Cambrigde Color Test. Visual Neuroscience (No Prelo).

Murahovschi J. A. (1994). Medula Espinhal 1- Disrafismo Espinhal (Mielomeningocele). In: Murahovschi J A, Editores. Pediatria Diagnóstico + Tratamento. São Paulo: Savier, 212. 
Norcia A M; Tyler C. (1978). Infant Vep Acuity Measurements: Analysis Of Individual Differences And Measurement Error. Eletroencephalography And Neurophysiology. 61, $359-369$.

Norcia, A. M.; Tyler, C. (1985b).Spatial frequency sweep vep: visual acuity during the first year of life. Vision Res. 25, 10, 1399-1408.

Norcia, A. M.; Tyler, C.; Piecuch, R.; Clyman, R.; Grobstein, J. (1987). Visual acuity development in normal and abnormal preterm human infants. J. Ped. Ophthalmol. Strab., $24,70-74$.

Odom, J.V. (2003). Funcional vision: assessment and outcome. Visual imparment Research, 5, 113-114.

Oliveira, A. G. F. et al. (2004). Contrast sensitivity threshold measured by sweep-visual evoked potencial in term and preterm infants at 3 and 10 months of age. Brazilian Journal of Medical and Biological Research 37, 1389-1396.

Paysse, E.A.; Khokhar, A; McCreery, K.M.B.; Morris, M.C.; Coats, D.K. (2002). UpSlating palpebral fissures and Oblique astigmatism associated with a-pattern strabismus and overdepression in adduction in spina bifida. Journal of AAPOS,12, 354-359. 
Pike, M.G.; Holmstrom, G.; de Vries, L.S.; Pennock, J.M.; Drew, K.J.; Sonksen,P.M.; \& Dubowitz, L.M.S. (1994). Patterns of visual imparment associated with lesions of the preterm infant brain. Development Medicine and Child Neurology, 36, 849-862.

Reinprecht, A.; Dietrich W; Berger A; Bavinzski G; Weninger $M_{i}$ Czech T. (2001). Posthemorrhagic hydrocephalus in preterm infants: long-term follow-up and shunt-related complications. Child's Neur. System. 663-669.

Rosemberg, S. (1997). Mielomeningoceles. In: In: Diament, A.; Cypel, S. editores. Neurologia Infantil. São Paulo: Atheneu, 208-209.

Roth, P. A.; Cohen, A.R. (1996). Management of hydrocephalus in infants and children, In: Tindall, G. T.; Cooper, P. R.; Barrow, D. L. (Eds): The practice of neurosurgery. Williams \& Wilkins, Baltimore, 3, 2707-2711.

Salomão, S.R.; Birch, E.E. Individual growth curves for infant visual acuity measured by sweep-VEP and Fpl [(abstract)] Invest. Ophthalmol. Vis. Sci., (1996), 37, 1067. [(Presented at annual meeting of ARVO; 1996. May 1-6; Forth Lauderdale (EUA).

Salomão, S.R.; Berezovsky, A.; Cinoto, R.W.; de Haro, F.M.B.; Ventura, D.F.; Birch, E.E. (2000). Longitudinal visual acuity development in heathy preterm infants [abstract]. Invest. Ophthalmol. Vis. Sci., 41, 728. [Presented at annual meeting of ARVO; 2000. May 15; Forth Lauderdale (EUA)]. 
Salomão, S.R.; Ventura, D.F. (1995). Large scale population age norms for visual acuities obtained with Vistech/Teller acuity cards. Invest Ophthalmol. Vis. Sci., 36, 657-670.

Hospital Sarah, DF. Recuperado em og de Junho de 2005. Rede Sarah de Hospitais de Reabilitação.

http://www.sarah.br

Schwartz, S. H. (2004). Visual Perception: A Clinical orientation. (3ed.). Mcgraw-Hill Companies.

Shepherd, R. B. (1996). Malformações congênitas. In: Fisioterapia e pediatria. Santos, $3^{\circ}$ ed, 238.

Shokumbi, MT; Odebode TO; Agbeja- Baiyeroju AM, Malomo AO; Ogunseyinde AO; Familusi JB. (2002). A comparison of visual function scores in hydrocephalic infants with and without lumbosacral myelomeningocoele, Eye, 16, 739-743.

Skarf,B. (1989). Clinical use of visual evoked potentials. Ophthalmol. Clin. North Am., 499-518.

Slater, A. (1989). Visual development. In: SLATER, A.; BREMNER, G. (Eds.) Infant Development. Lawrence Erlbaum Associates. 
Sokol, L. S. (1978). Measurement of infant visual acuity from pattern reversal evoked potentials. Vis. Res., 18, 33-39.

Spencer, R. MD. (2006). Long-Term Visual Outcomes In Extremely Low-Birth-Weight Children (An American Ophthalmological Society Thesis). Trans Am Ophthalmol Soc; 104: 493-516.

Sutton, L. N.; Sun, P.; Adzick, N. S. (2001). Fetal Neurosurgery. Neurosurgery, 48, 124142.

Tyler, C.W.; Apkarian, P.; Levi, D.M.; Nakayama, K. (1979). Rapid assessment of visual function: an electronic sweep techinique for the pattern visual evoked potential. Invest. Ophthalmol. Vis. Sci., 18, 703-713.

Tzekov, S.; Cherninkova, T. G. (1991-92). Neuroophthalmological Symtoms in Children Treated for Internal Hydrocephalus. Pediatr. Neurosurg. 17: 317-320.

Ventura, D. F. ; Gualtieri, M. ; Oliveira, A. G. F. De ; Costa, M. F. ; Quiros, P.; Salomão, S. R. ; Berezovsky, A. ; Sadun, F. ; Sadun, A. A. ; Carelli, V. (2007). Male Prevalence For Color Vision Defects In Leber's Hereditary Optic Neuropathy Asymptomatic Carriers Of The 11778/Nd4 Mutation. Investigative Ophtalmology \& Visual Science, V. 48 (5), 2362-2370. 
Vinck, A.; Maassen, B.; Mullaart, R.; Rotteveel, J. (2006). Arnold-Chiari-II malformation and cognitive functioning in spina bifida. J Neurol Neurosurg Psychiatry; 77: $1083-1086$.

Zeiner H K; Prigatano G P; Pollay M; Biscoe C B; Smith R V. (1985). Ocular Motility, Visual Acuity And Dysfunction Of Neuropsychological Impairment In Children With Shunted Uncomplicated Hydrocephalus. Child's Neur. System 1: 115-122.

Westheimer, G. (1992). In: Hart,W. ed.Adler's - Physiology of eye. Clinical Aplication. 9 th ed.St. Louis. Mosby, 170-187.

Woodhouse, J.M.; Adoh, T.O.; Oduwaike, K.A.; Batchelor, B.G.; Megji, S.; Unwin, N.; Jones, N. (1992). New acuity test for toldlers. Ophthal. Pshysiol. Opt.,12, 249-251. 